\title{
Complementary Analytical Methods for Analysis of Ag-Plated Cultural Heritage Objects \\ Matthew Carl ${ }^{1 *}$ and Marcus L. Young ${ }^{1}$ \\ ${ }^{1}$ Department of Materials Science and Engineering, University of North Texas, 1155 Union Circle, Denton, Texas 76203 USA \\ *Corresponding Author
}

\author{
E-mail address: matthewcarl@my.unt.edu
}

\begin{abstract}
In a preliminary study of American silver plated cultural heritage objects with the Dallas Museum of Art (DMA), variable plating thickness was observed, which complicates non-destructive characterization of the base metal. Therefore, it is the objective of this study is to compare the effectiveness of three nondestructive complementary analytical methods to characterize both the plating and base metal of a typical silver Ag-plated object and to contrast these results with conventional destructive metallographic methods. An externally purchased sacrificial "Century" fork was chosen for this study and is similar to one found in the DMA's collection. First conventional destructive metallographic methods, where crosssections were taken and then characterized using optical microscopy (OM) and scanning electron microscope (SEM) with energy dispersive X-ray spectroscopy (EDS), were employed in order to evaluate the effectiveness of the non-destructive methods. The first non-destructive method, synchrotron radiation $\mathrm{X}$-Ray diffraction (SR-XRD), reveals the plating thickness, texture related to processing methods, and the phases present in both the base metal and plating. The second method, dual beam focused ion beam (FIB) / (SEM) equipped with an (EDS) system, provides elemental composition of both the plating and base metal, as well as imaging of the plating thickness and grain structure, giving some insight into processing methods. The last non-destructive method, handheld X-Ray Fluorescence (XRF) spectroscopy, provides qualitative elemental compositions of both the plating and base metals. Each non-destructive analytical method yields complementary results about the composition, plating thickness, texture, and phases present in the plating and base metals of the Ag-plated "Century" fork and aids in the verification of the results from the other methods. Through these methods, we show that successful characterization of Agplated cultural heritage objects is possible non-destructively, thus maintaining the object's structural, historical and artistic integrity.
\end{abstract}

\section{Introduction}

In general, scientific studies of historical and cultural objects are focused on determining the provenance, condition, and manufacturing technologies of the people who produced them [1-4]. The analytical examination of silver and silver-plated cultural heritage objects is no exception [5-8]. Most of the past and present scientific studies of these silver or silver-plated objects, deal with on the examination of coins [9-22], or jewelry [23]from ancient and medieval cultures. Although some studies have been performed on more modern silver alloy objects [24-28], there still exist a void for the study and characterization of electroplated silver objects from the Modernist movement of the late $19^{\text {th }}$ and early $20^{\text {th }}$ Century.

It is the author's intent to fill this void by performing a systematic study of the Jewel Stern American Silver Collection at the Dallas Museum of Art (DMA) which contains over $400 \mathrm{Ag}$ and Ag-plate objects from the Modernist movement of the late 19th and early 20th Centuries. These objects have been well- 
documented historically in Modernism in American Silver [29], but there is still a need for a comprehensive technical study of these materials to gain better insight into the craftsmen and industrial manufacturers of these objects and the time period. This information can provide valuable information to conservators, historians, and current industrial manufacturers. Furthermore, the base metal compositions and processing are not well-documented for most of the objects in the DMA collection; however, evidence of changes in composition and processing have been periodically released by the manufacturers, e.g. through advertisements.

One of the major challenges with studying ancient and modern cultural heritage objects is that they must be non-destructively and non-invasively examined, which often requires a combination of analytical techniques for full or even partial characterization [30-35]. Analytical techniques, such as conventional laboratory X-ray diffraction (XRD) and X-ray fluorescence (XRF) allow for surface studies of the objects which are extremely beneficial for the study of corrosion products and surface treatments, but cannot properly examine the base material without prior knowledge of the underlying structure; furthermore, these surface studies can be misleading with respect to the base metal and difficult to interpret since many objects have alterations on the surface layers such as corrosion, tarnishes, patinas, plating, and post-excavation cleaning residues [36-39]. For example, Mass et al. [28] calculated an emission depth of $20.3 \mu \mathrm{m}$ for the $\mathrm{Cu} \mathrm{K} \alpha$ line through a pure Ag matrix, the case for silver alloys with an enriched surface layer or silver-plated copper, meaning that copper becomes almost undetectable in small quantities once plating depths reach greater than $20 \mu \mathrm{m}$. It should also be noted that both XRD and XRF can now be performed in situ using portable devices and both have become common practices in the analytical study of cultural heritage objects [40-46]. Studies on the base material can be performed non-destructively using synchrotron, neutron, and proton sources available at large user facilities due to their much greater penetration depths; however, it is difficult to examine large bodies of work due to the nature of these facilities [47-51].

In this paper, it is the aim to compare and contrast three complimentary "non-destructive" analytical techniques used in cultural heritage studies: 1) high energy (transmission mode) synchrotron radiation X-ray diffraction (SR-XRD), 2) focused ion beam (FIB)/scanning electron microscopy (SEM) milling, and 3) handheld XRF spectroscopy, on a sacrificial Ag-plated object from the Modernist movement, similar to an object in the DMA's collection but purchased for destructive examination, to determine an effective way to characterize both the plating and base metal. These results are then compared with conventional destructive metallography to validate the non-destructive methods. This comparison is then used to determine an effective method to reliably and quickly characterize Ag-plated objects from the American Modernist movement. In addition, it can be easily seen how the combination of these methods can be readily applied to many other questions in cultural heritage studies where a thick surface alteration, greater than $5 \mu \mathrm{m}$, is in an integral part of the piece as a whole.

\section{Methods}

The object chosen for this study, Figure 1, is a sacrificial $20^{\text {th }}$ Century International Silver Co. fork that was made for the Seaboard Airline (SAL) Railroad train system, referred to from here on as the "Century" fork. The "Century" fork measures $1.9 \times 2.5 \times 19.1 \mathrm{~cm}^{3}$. The "Century" fork is from the same manufacturer and line with the "Century" pattern as the "Century" flatware set (for the New York Central System's $20^{\text {th }}$-Century Limited train system) in the DMA's collection. In addition the "Century" flatware 
sets were intentionally plated with a thick silver layer to withstand heavy use by passengers while still maintaining their polished appearance. By selecting an object with a thicker Ag-plating it is now possible to explore the limits of each non-destructive technique. SR-XRD patterns were taken at the Advanced Photon Source (APS) in Argonne National Labs using transmission mode at a beam energy of $70 \mathrm{keV}$, beam size of $50 \times 200 \mu \mathrm{m}^{2}$ and exposure time of $2 \mathrm{~s}$ per frame. 2-D diffraction patterns was analyzed using Fit2D and a custom Matlab code provided by the beam line scientist at the APS. Non-destructive FIB/SEM was performed using an FEI Nova Nanolab 200 equipped with an EDAX energy dispersive Xray spectroscopy system (EDS) following the procedure outlined in Carl et al. [52], which follows the basic steps: 1) mount an object to the stage such that it can avoid contact with all parts of the microscope during tilting, 2) select a region of interest and tilt specimen $52^{\circ}$ from normal to align ion column perpendicular to the surface, 3$)$ deposit a thin layer of $\mathrm{Pt}(\sim 1-5 \mu \mathrm{m})$ to protect cross-section and avoid "curtaining" effect, 3) mill a rectangular pattern into surface to reveal a cross-section perpendicular to the surface of the object, and 4) clean the cross-sectional face using a low current ion beam. XRF spectra were gathered with a Bruker Tracer-III SD handheld XRF spectrometer using $304.8 \mu \mathrm{m} \mathrm{Al}$ and $25.4 \mu \mathrm{m}$ Ti filters at $40 \mathrm{keV}$ and $30 \mu \mathrm{A}$ to optimize detection of transition metals. All spectra were gathered for a live time of $120 \mathrm{~s}$. Artax software was used to fit the peak area of the $\mathrm{Zn} \mathrm{K}_{\alpha}$ and $\mathrm{K}_{\beta}$ peaks for thickness approximations. Conventional destructive metallography was performed after non-destructive testing by cutting cross-sections from the fork and hot mounting them in a conductive graphite mold. Microstructure of the cross-sections was revealed using a solution of $\mathrm{HNO}_{3}: \mathrm{H}_{2} \mathrm{O}$ at a 1:1 ratio. Optical micrographs were taken using a Zeiss Axio Lab.A1 microscope in bright field and captured using an Axiocam 105 color camera. Further microstructural and elemental characterization was performed using the same FEI Nova Nanolab 200 system as describe above. In order to check the accuracy of the EDS quantification method, two standard samples with known compositions as determined by manufacturer supplied inductively coupled plasma - optical emission spectroscopy (ICP-OES) data and a third sample which was closer in composition to our actual object but the manufacturer did not supply ICP-OES data, only supplied the targeted composition. The results are shown in Table 1.

\begin{tabular}{|c|r|r|r|r|r|c|}
\hline \multicolumn{7}{|c|}{ Table 1 - Manufacturer wt. \% composition data vs. measured EDS quantification } \\
\hline & \multicolumn{1}{|c|}{ C510 Bronze } & \multicolumn{2}{c|}{ C360 Brass } & \multicolumn{2}{c|}{ C770 Nickel Silver } \\
\hline & OES & EDS-SEM & OES & EDS-SEM & Aimed & EDS-SEM \\
\hline $\mathbf{C u}$ & 95.19 & $95.6(.2)$ & 61 & $64.5(.1)$ & 55 & $54.3(.3)$ \\
\hline $\mathbf{S n}$ & 4.6 & $4.4(.2)$ & - & - & - & - \\
\hline $\mathbf{P}$ & 0.1 & - & - & - & - & - \\
\hline $\mathbf{F e}$ & $<0.01$ & - & 0.041 & - & - & - \\
\hline $\mathbf{P b}$ & $<0.005$ & - & 2.501 & $1.5(.1)$ & - & - \\
\hline $\mathbf{N i}$ & $<0.05$ & - & - & - & 18 & $18.2(.2)$ \\
\hline $\mathbf{Z n}$ & 0.04 & - & 36.458 & $34.0(.1)$ & 27 & $27.4(.4)$ \\
\hline
\end{tabular}

\section{Results and Discussion}

\subsection{Synchrotron X-ray Diffraction}

Figure 1 illustrates the motion of the fork during diffraction measurements. Diffraction patterns were taken in $10 \mu \mathrm{m}$ steps as the fork was moved into the beam, thus generating different patterns with respect to position across the sample in order to isolate the plating layer from the base metal as much as possible. The boxes labeled a, b, and $\mathrm{c}$ in the schematic in Figure 1 correlate to the approximate beam position of the representative Debye-Scherrer diffraction rings shown in Figure 2a-c, respectively. One quarter of a 
Debye-Scherrer diffraction ring from 110-120 $\mu \mathrm{m}$ from the edge of the "Century" fork, which contains both the plating and the base metal, is shown in Figure 3. The plating material consists of pure FCC Ag, while the base metal consists of an FCC Cu-Zn-Ni solid solution alloy. Close examination of the rings show slight texturing in both the plating and base metals most likely associated with residual strain due to rolling of the base metal and/or an anneal to homogenize the grain structures after rolling and plating. The normalized 1-D integrated diffraction patterns are presented in Figure 4 as a function of distance from the edge of the "Century" fork. It is clear that only two distinct macroscopic layers exist, an approximately 40-50 micron thick Ag-plating and a FCC Cu-Zn-Ni solid solution alloy base metal. The lattice parameters were calculated to be $4.09 \AA$ and $3.65 \AA$ for the plating and base metal, respectively. The plating lattice parameter is in good agreement with the literature value for pure FCC Ag [53]. Using Vegard's law, $a_{A_{(1-\chi) B}}=(1-\chi) a_{A}+\chi a_{B}$ [54], and historical context (i.e. common base material and alloying elements used for flatware), the composition of the base metal can be estimated within a range. Figure 5 a-c presents room temperature lattice parameter as a function of composition for three binary systems, $\mathrm{Cu}-\mathrm{Ni}, \mathrm{Cu}-\mathrm{Zn}$, and $\mathrm{Ni}-\mathrm{Zn}$ [55], at compositions where only an FCC phase is thermodynamically stable. As illustrated in Figure 5c, if the base metal composition is assumed to be a binary $\mathrm{Cu}-\mathrm{Zn}$ alloy, only one composition, approximately $85 \mathrm{wt} . \% \mathrm{Cu}$ and $15 \mathrm{wt} . \% \mathrm{Zn}$, is possible for the measured lattice parameter $a=3.65 \AA$; however, by examination of the ternary Cu-Ni-Zn phase diagram in the a-phase region (i.e. FCC solid solution) and extending Vegard's law to include ternary compositions, isometric lattice parameter lines can be extrapolated and superimposed to produce a ternary phase diagram that allows for estimation of lattice parameter based on composition when in the FCC phase. This is done by mathematically rearranging Vegard's law to be a function of linear slopes rather than initial lattice parameters or in other words, based on expansion or contraction of the initial lattice size due to the addition of a solute atom. Figure 5a-c shows the linear fits for the $\mathrm{Cu}-\mathrm{Ni}, \mathrm{Cu}-\mathrm{Zn}$, and $\mathrm{Ni}-\mathrm{Zn}$ systems, respectively. As an example, in Figure 5a ( $\mathrm{Cu}-\mathrm{Ni}$ binary system), the trend line is of the common linear y $=\mathrm{mx}+\mathrm{b}$ form, where $\mathrm{y}$ is the calculated lattice parameter, $\mathrm{m}$ is the slope or expansion or contraction of the initial lattice size due to the addition of a solute atom, $\mathrm{x}$ is the weight percentage of solute, and $\mathrm{b}$ is the initial lattice parameter of pure $\mathrm{Cu}$. This fitted trend line is merely a rearrangement of the common form of Vegard's law. To extend this concept to ternary compositions, then all possible binary combinations must be considered, as shown in Figures 5a-c for $\mathrm{Cu}-\mathrm{Ni}, \mathrm{Cu}-\mathrm{Zn}$, and $\mathrm{Ni}-\mathrm{Zn}$ systems, respectively. Assuming that the base metal is mainly $\mathrm{Cu}$, brass, bronze, or nickel-silver, it is used as the solvent in this case and $\mathrm{Ni} / \mathrm{Zn}$ the solute atoms leading to the equation:

$$
a_{C u_{1-X-y} i_{X} Z n_{y}}=a_{C u}+X m_{C u-N i}+y m_{C u-Z n}
$$

Where $\mathrm{a}_{\mathrm{cu}}$ is the lattice parameter of pure $\mathrm{Cu}, \mathrm{X}$ is the weight percentage of $\mathrm{Ni}$, $\mathrm{y}$ is the weight percentage of $\mathrm{Zn}$, and $\mathrm{m}$ is the slope of the binary trend line for the respective system. Now the possible composition of the base metal can be assumed to lie somewhere on or near the extrapolated $3.65 \AA$ linear line in Figure 6.

\subsection{Focused Ion Beam/Scanning Electron Microscopy}

Secondary ion image of the cut out trench needed for viewing a cross-section from the bottom of the handle, which is perpendicular to the longitudinal direction of the "Century" fork, is shown in Figure 7. This image shows the amount of material removed $\left(\sim 50 \times 20 \mu \mathrm{m}^{2}\right)$ to obtain a cross-sectional viewing area of the Ag-plating and the base metal. The irregular shape of the removed material is due to having to extend the viewing depth to see the base metal. Pt was used to reduce the effect of curtaining caused by 
differential milling rates associated with inhomogeneous features on the surface such as varying grain orientations and other defects $[52,56]$. During the milling process, this cross-sectional viewing area can be seen using the electron column which interacts with the cross-sectional face at an incident angle of $52^{\circ}$.. This angle of $52^{\circ}$ is needed to orient the ion beam perpendicular to the surface for milling. As shown in Figure 8a, only the Pt and the plating can be observed at this angle. It was determined from the EDS spectra (not shown here) that the plating consists of $\sim 100 \% \mathrm{Ag}$ with trace amounts of Ga due to implanted $\mathrm{Ga}^{+}$ions from the milling procedure [57]. Grains associated with the Ag-plating can be observed in Figure $8 \mathrm{a}$ and are consistent with a homogenous FCC $\alpha$-phase Ag which also has visible annealing twins $[2,58]$. Once milling was completed, the "Century" fork was rotated to optimize the cross-sectional viewing area by creating an incident angle of $33^{\circ}$ at the cross-sectional face, as illustrated in Figure 8b. At this angle, it is now possible to observe the Ag-plating (labeled A, Figure 8b), the base metal (labeled B, Figure $8 \mathrm{~b}$ ), and the interface between the two. Once the base metal was reached, $\mathrm{Cu}$ begins to appear in the EDS spectra from the Ag-plated region due to redeposition [57] (Figure 9). Texture is observable in the base metal; however, it is not possible to quantify or easily identify grain structure. EDS Spectra from the base metal region mainly consists of $\mathrm{Cu}$ and $\mathrm{Ag}$ with small amounts of $\mathrm{Ni}$ and $\mathrm{Ga}$, the latter being implanted during milling. Quantification is difficult using EDS due to five factors: 1) electron beam interaction size (on the order of 1-2 microns), while the electron beam spot size is relatively small on the order of nanometers, the interaction volume is much larger and distorts the measurements [59], 2) detector orientation which changes the take-off angle being detected, 3) depth of the trench created which changes the working distance, 4) redeposition of $\mathrm{Ag}$ atoms from the plating, and 5) $\mathrm{Ga}^{+}$ion implantation. Due to the nature of the cross-section, it is difficult to give any estimation of the base composition using this method especially when plating thickness is so thick, measured approximately $37 \mu \mathrm{m}$ at this location. Based on this method, the alloy appears to consist of $\mathrm{Cu}-\mathrm{Ni}$ only, where $\mathrm{Zn}$ is not detected. The missing $\mathrm{Zn} \mathrm{L}$ peak with an energy of $1.01 \mathrm{keV}$ is likely not visible since its intensity is much lower than $\mathrm{Cu}$ and the $\mathrm{Zn} \mathrm{L}$ peak would fall between the $\mathrm{Cu}$ and $\mathrm{Ga} \mathrm{L}$ peaks. While accurate quantification is complicated, the FIB/SEM method does allow for a qualitative understanding of both composition and the Ag-plating and base metal.

\subsection{Handheld XRF}

Figure 11a shows the three handheld XRF spectra, locations shown in Figure 10, with normalized intensity and offset for clarity from the underside of the "Century" fork. No spectra were taken from the topside of the "Century" fork because of the striations associated with the design that create an uneven surface which is not optimal for XRF measurements [60]. All three spectra are nearly identical indicating a homogenous Ag-plating. The Ag peaks associated with the Ag-plating dominate the XRF spectra. As shown in the detailed section of the energy range between 7-10 keV in Figure $11 \mathrm{~b}, \mathrm{Cu}$ and $\mathrm{Zn}$ peaks are present and quantification of the base metal is not possible without the use of an empirical calibration by standards coupled with fundamental parameters calculations [61] or Monte Carlo simulations [62] and only when an element does not exist in both layers. However, thickness of the plating can be estimated as explained in the following text. The first two XRF spectra (labeled A and B in Figure 10 and Figure 11) were taken along the handle, while the last XRF spectrum (labeled $\mathrm{C}$ in Figure 10 and Figure 11) was taken on the backside of the face, at the flattest location possible, where it was thought to have a thinner layer of Ag-plating due to normal wear during usage. A qualitative examination of the spectra shows very intense $\mathrm{Ag} \mathrm{K}$ and $\mathrm{L}$ level peaks and very small $\mathrm{Cu}, \mathrm{Ni}$, and $\mathrm{Zn} \mathrm{K}$ level peaks. As expected, the XRF spectrum collected from the backside of the face of the fork exhibits the highest $\mathrm{Cu}, \mathrm{Ni}$, and $\mathrm{Zn}$ peaks and has the highest potential for best identification of the base metal, due to the thinner amount of plating 
associated with wear. To obtain quantitative results for plating thickness, a simple model was employed based on the propagation of the fluorescent $\mathrm{Zn} \mathrm{X-rays} \mathrm{through} \mathrm{a} \mathrm{pure} \mathrm{Ag-matrix.} \mathrm{Starting} \mathrm{from} \mathrm{the} \mathrm{well-}$ known equation for $\mathrm{x}$-ray attenuation:

$$
I=I_{0} e^{-(\mu \rho) x}
$$

Where $I$ and $I_{0}$ are the final intensity and initial intensity respectively, $\mu$ is the mass absorption of the material at a certain $x$-ray energy value, $\rho$ is the density of the material, and $x$ is the thickness. If it is assumed that the fluorescent x-ray must propagate through a matrix of pure Ag then the equation can be rearranged to solve for $\mathrm{x}$ or plating thickness, which leads to:

$$
x=-\ln \left(\frac{I}{I_{0}}\right) /[(\mu \rho)]
$$

Knowing that the intensity ratio $\mathrm{K}_{\mathrm{a}} / \mathrm{K}_{\mathrm{B}}$ is a well-defined probability for a given element, this ratio can be used as an intrinsic $I_{0}$ value, or the intensity ratio when the fluorescent x-rays do not have to propagate through a Ag matrix before reaching the detector. This can be mathematically modeled by the equation:

$$
\frac{K_{\alpha}}{K_{\beta}}=\frac{I_{K_{\alpha}} / I_{K_{\alpha 0}}}{I_{K_{\beta}} / I_{K_{\beta 0}}}=\frac{e^{-\left(\mu_{1} \rho\right) x}}{e^{-\left(\mu_{2} \rho\right) x}}
$$

Where $\mu_{1}$ and $\mu_{2}$ are the mass absorption for $K_{\alpha}$ and $K_{B}$ energies, respectively. Rearranging and solving for $\mathrm{x}$ yields the following solution:

$$
x=\frac{[\ln (y)-\ln (C)]}{\left(\mu_{2}-\mu_{1}\right) \rho}
$$

Where $y$ is the measured $K_{a} / K_{B}$ intensity ratio and $C$ is $K_{a} / K_{B}$ when no plating is present. The model employed in this study gives values for the net intensity ratio of the $\mathrm{Zn} \mathrm{K}_{\alpha} / \mathrm{K}_{\mathrm{B}}$ peaks as a function of $\mathrm{Ag}$ plating thickness; Zn was chosen since its fluorescent yield and $\mathrm{K}$ level X-ray energies are the highest observed in the base metal and therefore would propagate the farthest through the plating. A common industrial C770 nickel silver, 55 wt.\% Cu-27 wt.\% Zn-18 wt.\% Ni, was used as a standard to determine a value for the ratio when no Ag-plating is present $\left(\mathrm{C}=\mathrm{Zn}\left(\mathrm{K}_{\mathrm{a}} / \mathrm{K}_{\mathrm{B}}\right)_{\mathrm{o}}=12.1\right)$ since its composition is at the very least similar in elemental constituents to the base metal of the fork and would allow for matrix effects such as secondary and ternary fluorescents to be considered. The results of these calculations are presented in Figure 12. It should be noted that significant error exist in the calculation of the intensity ratio due to the low counts associated with the measurement of the peak area of both the $\mathrm{Zn} \mathrm{K}_{\mathrm{a}}$ and $\mathrm{K}_{B}$ peaks, especially for the case of $\mathrm{A}$ and $\mathrm{B}$, and thus these value should be taken as estimates and not absolute measurements. As expected, the theoretical curve is an exponential function that clearly illustrates the exponentially decreasing relationship to Ag-plating thickness and measured intensity ratio. Accordingly, as Ag-plating thickness decreases, the intensity ratio of the $\mathrm{Zn} \mathrm{K} / \mathrm{K}_{\mathrm{B}}$ increases, making it possible to estimate plating thickness from XRF measurements. By this method, plating thickness is estimated to be 49, 44, and $29 \mu \mathrm{m}$ for the spots labeled A, B, and C in Figure 10 respectively.

\subsection{Conventional Metallography}

After the non-destructive testing was completed, two cross-sections were cut from the "Century" fork, Figure 10, for conventional destructive metallographic analysis. One perpendicular to the longitudinal direction, black line in Figure 10, and the other perpendicular to the transverse direction, white line in Figure 10, and subsequently mounted, polished, etched, and examined using OM and SEM. As seen in the 
OM images in Figure 13 a-c, no obvious texture associated with rolling or another mechanical manufacturing process is evident in either the plating or the base metal. The interface between the plating and the base metal is very sharp, linear, and non-porous, which isn't always the case in modern American Ag-plated objects [52]. The base metal, Figure 13c exhibits microstructure which consists of equiaxed $\alpha$ phase FCC grains on the order of $25 \mu \mathrm{m}$ with visible annealing twins and no indication of a second phase is present. Measured plating thickness, which is dependent upon location, was found to be $60 \mu \mathrm{m}$ for a thick (Figure 13a) and $35 \mu \mathrm{m}$ for a thin (Figure 13b) plating, respectively. Nominal compositions of both the plating and the base metal as measured using EDS are presented in Table 2.

Table 2 - Average Compositions of "Century" Fork by EDS in the SEM

\begin{tabular}{|c|c|c|c|c|c|c|c|c|}
\hline & \multicolumn{2}{|l|}{ Ag } & \multicolumn{2}{|l|}{$\mathbf{C u}$} & \multicolumn{2}{|l|}{$\mathbf{Z n}$} & \multicolumn{2}{|l|}{$\mathbf{N i}$} \\
\hline & at. \% & wt. \% & at. $\%$ & wt. \% & at. $\%$ & wt. \% & at. \% & wt. \% \\
\hline Base & - & - & $68.7(2.1)$ & $69.0(2.1)$ & $19.4(0.9)$ & $20.0(0.9)$ & $11.9(1.4)$ & $11.0(1.3)$ \\
\hline Plating & $98.4(1.0)$ & $99.0(0.6)$ & $0.2(0.4)$ & $0.5(0.2)$ & $0.7(0.6)$ & $0.4(0.4)$ & $0.2(0.3)$ & $0.1(0.2)$ \\
\hline
\end{tabular}

As expected the plating is almost $100 \% \mathrm{Ag}$ because of the electrodeposition process and the base metal appears to be an FCC solid solution (and confirmed by SR-XRD) of approximately $69 \mathrm{wt} . \% \mathrm{Cu}-20$ wt.\%Zn-11 wt.\%Ni. Comparing the values for the measured composition for the base metal with Figure 6 , it can be seen that the actual composition lies very near to the expected composition line generated using Vegard's Law thereby verifying the validity of the method used in the SR-XRD measurements. Figure 14a shows an SEM image of the plating, base metal, and the interface between the plating and the base metal. The line scan shown in Figure 14a and the elemental maps from EDS for $\mathrm{Ag}, \mathrm{Cu}, \mathrm{Ni}$, and $\mathrm{Zn}$ in Figure 14b-e, respectively, confirm that both the base metal and plating region were homogenous and that no clustering or major diffusion had taken place in the plating, base metal, or at the interface between the plating and the base metal.

\subsection{Comparison of the three non-destructive techniques}

Of the three non-destructive techniques, SR-XRD measurements generated the most information such as phases present, local plating thickness, texture analysis (i.e. potential processing methods), and an estimation of composition for the base metal. However due to the nature of synchrotron facilities, SRXRD experiments requires transportation of objects, which can be very difficult especially for cultural objects of high value, and beam time approval [47]. In addition, although it was not performed in this study, it is also possible with aid of standards to determine grain size based on peak broadening observed in diffraction patterns $[63,64]$

SEM/FIB also yielded valuable information such as local grain structure of the Ag-plating, local plating thickness, composition of the plated region, and a qualitative understanding of the base metal by correctly identifying $\mathrm{Cu}$ and $\mathrm{Ni}$ as major elements in the base metal, although the presence of $\mathrm{Zn}$ was missed. Also, the method allowed for a microscopic investigation of the interface that was shown to be sharp and free of porosity at least locally in the area of examination. The visualization of the plating's grain structure, allowed due to the highly polished surface associated with ion milling, revealed annealing twins and led to the suggestion of a possible homogenization treatment post electrodeposition. However in this case, the SEM/FIB method suffered greatly from the thickness of the Ag-plating. When plating layers are thin $(\leq 80 \mu \mathrm{m})$ [52]; a wealth of information such as plating thickness, uniformity, porosity, local grain structure, and composition and base metal local grain structure and composition can be obtained. As the thickness of the plating is increased, more material must be removed in order to observe 
the base metal, thus limiting the technique. In this case, however, for the $\sim 35 \mu \mathrm{m}$ Ag-plating "Century" fork not all minor elements such as $\mathrm{Zn}$ were detectable for the base metal.

Likewise, handheld XRF spectroscopy allow for a qualitative identification of the three alloying elements in the base metal $(\mathrm{Cu}, \mathrm{Ni}$, and $\mathrm{Zn})$ and also allowed for a quick, semi-quantitative estimation of the plating thickness at the measured position by examination of the intensity ratio of the $\mathrm{Zn} \mathrm{K}_{\mathrm{a}} / \mathrm{K}_{\mathrm{B}}$ peaks. This was possible only due to having prior knowledge of the underlying macrostructure of the object (i.e. pure Ag-plating due to electrodeposition on a substrate). However, since XRF measurements have no inherent information of depth, it is not possible to quantify the nominal composition of either the Agplating or base metal because the information cannot be decoupled by examination of the spectra alone. It may however be possible to replicate Ag-plated standards with varying plating thicknesses and of similar compositions to create an empirical calibration [60] that can be used to quantify the base metal if it is assumed that the composition of the plating is very close to $100 \%$ pure $\mathrm{Ag}$, as suggested by electrodeposition.

\section{Conclusions}

Both non-destructive and conventional metallographic analysis methods were used to examine a $20^{\text {th }}$ century sacrificial Ag-plated "Century" fork from the DMA's collection of Ag and Ag-plated objects from the Modernist movement of the late $19^{\text {th }}$ and early $20^{\text {th }}$ centuries in order to compare the effectiveness and validity of each method. From each non-destructive method, complimentary information was gained and the following conclusions can be made:

1. SR-XRD experiments allowed for identification of phases present, plating thickness, texture related to processing, and an estimation of the composition based on Vegard's Law and lattice parameter measurements.

2. SEM/FIB experiments allowed for identification of the overall microstructure, local grain structure of the Ag-plating, local plating thickness, composition of the plated region, and a qualitative understanding of the base metal, by identifying $\mathrm{Cu}$ and $\mathrm{Ni}$ as major elements in the base metal, although the minor element $\mathrm{Zn}$ was not detectable likely due to peak overlaps with $\mathrm{Cu}$ and $\mathrm{Ga}$.

3. Handheld XRF experiments allowed for a qualitative identification of the three alloying elements in the base metal $(\mathrm{Cu}, \mathrm{Ni}$, and $\mathrm{Zn})$ and also allowed for a quick, semi-quantitative estimation of the plating thickness.

Destructive examination of the object using conventional metallography validated the results from nondestructive methods for information like composition, grain structure, processing methods, and plating thickness. Although all the non-destructive methods gave varying degrees of information, none of them alone would be sufficient in order to fully characterize an Ag-plated cultural heritage object; thus, reconfirming the need for multiple advanced characterization techniques. It is the aim of our future research to create a database that can be used to effectively and efficiently characterize Ag-plated objects using only handheld XRF measurements through the use of empirical standards and non-destructive examination of cultural heritage objects.

\section{Acknowledgements}

The authors would like to thank Fran Baas, Mark Leonard, and Kevin Tucker from the Dallas Museum of Art for assistance with the handheld XRF spectrometer and for their contributions to the project. Synchrotron X-ray diffraction measurements were performed at the X-ray Operations and 
Research beamline 1-ID at the Advanced Photon Source, Argonne National Laboratory with the assistance of Drs. Jon Almer and Jun-Sang Park. The authors acknowledge the use of the experimental facilities at the Center for Advanced Research and Technology (CART) at the University of North Texas. Part of this research was performed at the Advanced Photon Source, a U.S. Department of Energy (DOE) Office of Science User Facility operated for the DOE Office of Science by Argonne National Laboratory under Contract No. DE-AC02-06CH11357.

\section{References}

[1] E. Ciliberto, G. Spoto, Modern Analytical Methods in Art and Archaeology, John Wiley \& Sons, New York, 2000.

[2] D.A. Scott, Metallography and Microstructure in Ancient and Historic Metals, J. Paul Getty Museum, Singapore, 1991.

[3] C. Lahanier, F.D. Preusser, L. Van Zelst, Study and Conservation of Museum Objects: Use of Classical Analytical Techniques, Nuclear Instruments \& Methods in Phys. Res. B, 14 (1986) 1-9.

[4] E. Pernicka, Provenance Determination of Metal Artifacts: Methodological Considerations, Nuclear Instruments \& Methods in Phys. Res. B, 14 (1986) 24-29.

[5] S. La-Niece, Metal plating and patination: cultural, technical and historical developments, Elsevier, 2013.

[6] R. Borges, I. Tissot, A.I. Seruya, C. Silva, J. Rui, S. Fragoso, B. Maduro, A. Pais, Gilding and silvering surface decoration techniques, and copper provenance studies of the tomb of $D$. Afonso of Portugal (15th century), X-Ray Spectrometry, 37 (2008) 338-345.

[7] M.F. Guerra, The study of the characterisation and provenance of coins and other metal work using XRF, PIXE and Activation Analysis, Radiation in Art and Archeometry. Amsterdam: Elsevier, (2000) 378416.

[8] R. Linke, M. Sehreiner, G. Demortier, M. Alram, H. Winter, Chapter 13 The provenance of medieval silver coins: analysis with EDXRF, SEM/EDX and PIXE, Comprehensive Analytical Chemistry, Elsevier, 2004, pp. 605-633.

[9] K. Anheuser, J.P. Northover, Silverplating on Roman and Celtic coins from Britain-a technical study, The British Numismatic Journal, 64 (1994) 22-24.

[10] A. Deraisme, L. Beck, F. Pilon, J.N. BARRANDON, A STUDY OF THE SILVERING PROCESS OF THE GALLO-ROMAN COINS FORGED DURING THE THIRD CENTURY AD*, Archaeometry, 48 (2006) 469-480.

[11] J.M. del Hoyo-Meléndez, P. Świt, M. Matosz, M. Woźniak, A. Klisińska-Kopacz, Ł. Bratasz, Micro-XRF analysis of silver coins from medieval Poland, Nuclear Instruments and Methods in Physics Research Section B: Beam Interactions with Materials and Atoms, 349 (2015) 6-16.

[12] I. Gržetić, J. Orlić, V. Radić, M. Radić, K. Ilijević, Analysis of medieval Serbian silver coins from XIV and XV century by means of wavelength-dispersive X-ray spectrometry, Nuclear Instruments and Methods in Physics Research Section B: Beam Interactions with Materials and Atoms, 366 (2016) 161170.

[13] G.M. Ingo, S. Balbi, T. De Caro, I. Fragala, C. Riccucci, G. Bultrini, Microchemical investigation of Greek and Roman silver and gold plated coins: coating techniques and corrosion mechanisms, Appl. Phys. A, 83 (2006) 623-629.

[14] F. Rizzo, G. Cirrone, G. Cuttone, A. Esposito, S. Garraffo, G. Pappalardo, L. Pappalardo, F. Romano, S. Russo, Non-destructive determination of the silver content in Roman coins (nummi), dated to 308-311 AD, by the combined use of PIXE-alpha, XRF and DPAA techniques, Microchemical Journal, 97 (2011) 286-290. 
[15] F. Romano, S. Garraffo, L. Pappalardo, F. Rizzo, In situ investigation of the surface silvering of late Roman coins by combined use of high energy broad-beam and low energy micro-beam X-ray fluorescence techniques, Spectrochimica Acta Part B: Atomic Spectroscopy, 73 (2012) 13-19. [16] M. Rodrigues, M. Schreiner, M. Mäder, M. Melcher, M. Guerra, J. Salomon, M. Radtke, M. Alram, N. Schindel, The hoard of Beçin-non-destructive analysis of the silver coins, Applied Physics A-Materials Science \& Processing, 99 (2010) 351-356.

[17] A. Buccolieri, G. Buccolieri, E. Filippo, D. Manno, G. Sarcinelli, A. Siciliano, R. Vitale, A. Serra, Nondestructive Analysis of Silver Coins Minted in Taras (South Italy) between the $\mathrm{V}$ and the III Centuries BC, Journal of Archaeology, 2014 (2014).

[18] F. Caridi, L. Torrisi, M. Cutroneo, F. Barreca, C. Gentile, T. Serafino, D. Castrizio, XPS and XRF depth patina profiles of ancient silver coins, Applied Surface Science, 272 (2013) 82-87.

[19] A. Moreno-Suárez, F. Ager, S. Scrivano, I. Ortega-Feliu, B. Gómez-Tubío, M. Respaldiza, First attempt to obtain the bulk composition of ancient silver-copper coins by using XRF and GRT, Nuclear Instruments and Methods in Physics Research Section B: Beam Interactions with Materials and Atoms, 358 (2015) 93-97.

[20] E. Pańczyk, B. Sartowska, L. Waliś, J. Dudek, W. Weker, M. Widawski, The origin and chronology of medieval silver coins based on the analysis of chemical composition, Nukleonika, 60 (2015) 657-663.

[21] Z. Kasztovsky, Non-destructive analysis of historical silver coins, Analytical applications of nuclear techniques, 2004.

[22] V. Kantarelou, F.J. Ager, D. Eugenidou, F. Chaves, A. Andreou, E. Kontou, N. Katsikosta, M.A. Respaldiza, P. Serafin, D. Sokaras, X-ray Fluorescence analytical criteria to assess the fineness of ancient silver coins: Application on Ptolemaic coinage, spectrochimica Acta part B: Atomic spectroscopy, 66 (2011) 681-690.

[23] H. Fajfar, Z. Rupnik, Ž. Šmit, Analysis of metals with luster: Roman brass and silver, Nuclear Instruments and Methods in Physics Research Section B: Beam Interactions with Materials and Atoms, 362 (2015) 194-201.

[24] M.F. Guerra, P. Núñez-Regueiro, Indigenous silver jewellery of Northern Patagonia (19th century): a first analytical approach to composite objects, X-Ray Spectrometry, 41 (2012) 342-349.

[25] A. Pitarch, I. Queralt, A. Alvarez-Perez, Analysis of Catalonian silver coins from the Spanish war of independence period (1808-1814) by energy dispersive X-ray fluorescence, Nuclear Instruments and Methods in Physics Research Section B: Beam Interactions with Materials and Atoms, 269 (2011) 308312.

[26] I.M.G. Quimby, D. Johnson, American Silver At Winterthur, Henry Francis du Pont Winterthur Museum, Winterthur, Delaware, 1995.

[27] J.L. Mass, C.R. Matsen, Understanding silver hollow wares of the eighteenth and nineteenth centuries: Is there a role for X-ray fluorescence?, The Decorative: Conservation and the Applied Arts. 2012 IIC Congress, The International Institute for Conservation of Historic and Artistic Works, Vienna, 2012, pp. S191-S198.

[28] J. Mass, C. Matsen, Quantitative non-destructive analysis of historic silver alloys: X-ray fluorescence approaches and challenges, Handheld XRF for Art and Archaeology, 3 (2012) 215.

[29] J. Stern, Modernism in American Silver: 20th-Century Design, Yale University Press, New Haven, CT, 2005.

[30] M. Menu, Analysis of works of art down to the nanometric scale, Microelectronic Engineering, 83 (2006) 597-603.

[31] B. Constantinescu, A. Săşianu, R. Bugoi, Adulterations in first century bc: the case of Greek silver drachmae analyzed by X-ray methods, Spectrochimica Acta Part B: Atomic Spectroscopy, 58 (2003) 759765. 
[32] A. De Ryck, A. Adriaens, E. Pantos, F. Adams, A comparison of microbeam techniques for the analysis of corroded ancient bronze objects, The Analyst, (2003) 1104-1109.

[33] P. Northover, A. Crossley, C. Grazioli, N. Zema, S. La Rosa, L. Lozzi, P. Picozzi, E. Paparazzo, A multitechnique study of archeological bronzes, Surface and Interface Analysis, 40 (2008) 464-468.

[34] G.M. Ingo, G. Guida, E. Angelini, G. Di Carlo, A. Mezzi, G. Padeletti, Ancient mercury-based plating methods: combined use of surface analytical techniques for the study of manufacturing process and degradation phenomena, Accounts of chemical research, 46 (2013) 2365-2375.

[35] I. Crina Anca Sandu, M.H. de Sá, M.C. Pereira, Ancient 'gilded'art objects from European cultural heritage: a review on different scales of characterization, Surface and Interface Analysis, 43 (2011) 11341151.

[36] A. Giumlia-Mair, On surface analysis and archaeometallurgy, Nuclear Instruments \& Methods in Phys. Res. B, 239 (2005) 35-43.

[37] J. Tate, Some problems in analysing museum material by nondestructive surface sensitive techniques, Nuclear Instruments and Methods in Physics Research Section B: Beam Interactions with Materials and Atoms, 14 (1986) 20-23.

[38] L. Beck, S. Bosonnet, S. Réveillon, D. Eliot, F. Pilon, Silver surface enrichment of silver-copper alloys: a limitation for the analysis of ancient silver coins by surface techniques, Nuclear Instruments and Methods in Physics Research Section B: Beam Interactions with Materials and Atoms, 226 (2004) 153162.

[39] P. Lejcek, J. Kovac, J. Vanickova, J. Ded, Z. Samardzija, A. Zalar, Copper surface enrichment of Ag-Cu alloys, Surface and Interface Analysis, 42 (2010) 662-665.

[40] I. Nakai, Y. Abe, Portable X-ray powder diffractometer for the analysis of art and archaeological materials, Appl. Phys. A, 106 (2012) 279-293.

[41] M. Eveno, A. Duran, J. Castaing, A portable X-ray diffraction apparatus for in situ analyses of masters' paintings, Appl. Phys. A, 100 (2010) 577-584.

[42] P. Sarrazin, G. Chiari, M. Gailhanou, A portable non-invasive XRD-XRF instrument for the study of art objects, Denver X-Ray Conference, JCPDS-International Centre for Diffraction Data USA, 2008, pp. 175186.

[43] A. Gianoncelli, J. Castaing, L. Ortega, E. Dooryhee, J. Salomon, P. Walter, J.L. Hodeau, P. Bordet, A portable instrument for in situ determination of the chemical and phase compositions of cultural heritage objects, X-Ray Spectrometry, 37 (2008) 418-423.

[44] A.M. Cuevas, H.P. Gravie, Portable energy dispersive X-ray fluorescence and X-ray diffraction and radiography system for archaeometry, Nuclear Instruments and Methods in Physics Research Section A: Accelerators, Spectrometers, Detectors and Associated Equipment, 633 (2011) 72-78.

[45] M. Eveno, B. Moignard, J. Castaing, Portable apparatus for in situ X-ray diffraction and fluorescence analyses of artworks, Microscopy and Microanalysis, 17 (2011) 667-673.

[46] L. Beck, H. Rousselière, J. Castaing, A. Duran, M. Lebon, B. Moignard, F. Plassard, First use of portable system coupling X-ray diffraction and X-ray fluorescence for in-situ analysis of prehistoric rock art, Talanta, 129 (2014) 459-464.

[47] M.L. Young, Archaeometallurgy using synchrotron radiation: a review, Reports on Progress in Physics, 75 (2012) 036504.

[48] G. Harbottle, B.M. Gordon, K.W. Jones, Use of synchrotron radiation in archaeometry, Nuclear Instruments \& Methods in Phys. Res. B, 14 (1986) 116-122.

[49] J.-C. Dran, J. Salomon, T. Calligaro, P. Walter, lon beam analysis of art works: 14 years of use in the Louvre, Nuclear Instruments and Methods in Physics Research Section B: Beam Interactions with Materials and Atoms, 219-220 (2004) 7-15.

[50] L. Bertrand, M. Cotte, M. Stampanoni, M. Thoury, F. Marone, S. Schöder, Development and trends in synchrotron studies of ancient and historical materials, Physics Reports, 519 (2012) 51-96. 
[51] B. Newbury, B. Stephenson, J.D. Almer, M. Notis, G.S. Cargill, G.B. Stephenson, D.R. Haeffner, Synchrotron Applications in Archaeometallurgy: Analysis of High Zinc Brass Astrolabes, Powder Diffraction, 19 (2004) 12-15.

[52] M. Carl, C.A. Smith, M.L. Young, Dual-Beam Scanning Electron Microscope (SEM) and Focused Ion Beam (FIB): A Practical Method for Characterization of Small Cultural Heritage Objects, MRS

Proceedings, Cambridge Univ Press, 2014, pp. mrsf13-1656-pp1603-1602.

[53] E. Prince, A.J.C. Wilson, T. Hahn, U. Shmueli, International tables for crystallography, International Union of Crystallography, 1999.

[54] D.R. Gaskell, Introduction to the Thermodynamics of Materials, CRC Press, 2008.

[55] W.B. Pearson, A Handbook of Lattice Spacings and Structures of Metals and Alloys: International Series of Monographs on Metal Physics and Physical Metallurgy, Elsevier, 2013.

[56] L.A. Giannuzzi, N.C.S. University, Introduction to Focused Ion Beams: Instrumentation, Theory, Techniques and Practice, Springer US, 2006.

[57] M.K. Miller, K.F. Russell, Atom probe specimen preparation with a dual beam SEM/FIB miller, Ultramicroscopy, 107 (2007) 761-766.

[58] M. Grimwade, Introduction to Precious Metals: Metallurgy for Jewelers \& Silversmiths, Brynmorgen Press, Brunswick, Maine, USA, 2009.

[59] J. Goldstein, D.E. Newbury, D.C. Joy, C.E. Lyman, P. Echlin, E. Lifshin, L. Sawyer, J.R. Michael, Scanning Electron Microscopy and X-ray Microanalysis: Third Edition, Springer US, 2012.

[60] A.N. Shugar, J.L. Mass, Handheld XRF for Art and Archaeology, Leuven University Press, Leuven, 2012.

[61] M. Ferretti, C. Polese, C. Roldán García, X-ray fluorescence investigation of gilded and enamelled silver: The case study of four medieval processional crosses from central Italy, Spectrochimica Acta Part B: Atomic Spectroscopy, 83-84 21-27.

[62] T. Schoonjans, V.A. Solé, L. Vincze, M. Sanchez del Rio, K. Appel, C. Ferrero, A general Monte Carlo simulation of energy-dispersive X-ray fluorescence spectrometers - Part 6. Quantification through iterative simulations, Spectrochimica Acta Part B: Atomic Spectroscopy, 82 (2013) 36-41.

[63] I.C. Noyan, J.B. Cohen, Residual stress: measurement by diffraction and interpretation, SpringerVerlag, 2013.

[64] H.P. Klug, L.E. Alexander, X-ray diffraction procedures, (1954). 


\section{Figure Captions:}

Figure $1-20^{\text {th }}$ Century International Silver Co. fork from the Seaboard Airline Railroad train system with a "Century" pattern showing transverse (TD) and longitudinal direction (LD). The arrow shows the motion of the "Century" fork for SR-XRD for positions a, b, and c in Figure 2.

Figure 2 - Example SR-XRD patterns from the "Century" fork at three different positions: a) mostly in air, but grazing the Ag-plating (0-10 $\mu \mathrm{m}$ from the edge), b) plating-only region near the edge (20-30 $\mu \mathrm{m}$ from the edge), and c) two layers of Ag-plating (front- and back-side) and the bulk material (110-120 $\mu \mathrm{m}$ from the edge).

Figure 3 - One quarter of a DeBye-Scherrer diffraction ring 110-120 $\mu \mathrm{m}$ from the edge of the "Century" fork, which contains both the pure FCC Ag-plating and the bulk material, a FCC Cu-Zn-Ni solid solution alloy.

Figure 4 - Normalized 1-D diffraction patterns with a $10 \mu \mathrm{m}$ (step size) offset. High background associated with first spectrum $(\sim 0 \mu \mathrm{m})$ is due to the beam only partial making contact with the fork. The labels (a), (b), and (c) refer to the position of the diffraction patterns shown in Figure 2 a-c.

Figure 5 - Room temperature lattice parameters for a) $\mathrm{Cu}-\mathrm{Ni}$, b) $\mathrm{Cu}-\mathrm{Zn}$, and c) Ni-Zn FCC solid solutions as a function of composition [81].

Figure 6 - Cu-Ni-Zn ternary phase diagram highlighting the $\alpha$-phase (FCC solid solution) with overlayed, extrapolated isometric lattice parameter lines. The dashed line represents $a=3.65 \AA$ indicating that possible compositions of bulk material lie along this line. The triangle represents the composition of the bulk material from the "Century" fork as measured during destructive test using EDS.

Figure 7 - Secondary ion image of the cut out trench needed for viewing a cross-section from the bottom of the handle, which is perpendicular to the longitudinal direction of the "Century" fork.

Figure 8 - SEM images of the cross-sectional viewing area from the bottom of the handle of the "Century" fork at a) an incident angle of $52^{\circ}$ and b) $33^{\circ}$ with respect to the cross-section face. Regions labeled (A) and (B) correspond to the plating and bulk material, respectively. Deposited Pt strip is visible at the top of the image. 
Figure 9 - EDS spectra for plating region (A) and bulk material (B) from the SEM image of the crosssectional viewing area at an incident angle of $33^{\circ}$ with respect to the cross-section face (Figure $8 \mathrm{~b}$ ) from the bottom of the handle of the "Century" fork.

Figure 10 - Underside of "Century" fork after sectioning of the handle region. "T" reflects orientation of cross-sections presented in Figure 13a-b. The black line corresponds to the transverse direction, Figure 13a, and the white line to the longitudinal direction, Figure 13b. Blue (A), red (B), and green (C) ovals show approximate beam size $(\sim 3 \mathrm{~mm})$ and location of handheld XRF measurements.

Figure 11 - Handheld XRF spectra from three different locations (labeled with ovals A (blue), B (red), and $\mathrm{C}$ (green) here and on the image of the "Century" fork in Figure 10) within an energy range of a) 0-30 $\mathrm{keV}$ and b) 7-10 keV. Purple box in (a) shows the region detailed in (b).

Figure 12 - Curve showing the theoretical plating thickness as a function of the intensity ratio of $\mathrm{Zn}$ $\mathrm{K}_{\alpha} / \mathrm{K}_{\mathrm{B}}$. Markers on the curve are color coordinated with Figure 10a-b (i.e. blue, red, and green dots correspond to 49,44 , and $29 \mu \mathrm{m}$, respectively) and represent the measured values for the Zn intensity ratios of the three handheld XRF spectra collected. A, B, and C correlate to ovals in Figure 10 and spectra in Figure 11a and $\mathrm{b}$.

Figure 13 - Bright field OM images from the two cross-sections taken from the handle of the "Century" fork in the (a) transverse direction (black line Figure 12) and (b) longitudinal direction (white line Figure 12) showing both the Ag-plating and the bulk material and (c) only the bulk of the material taken from the center of the cross-section in the transverse direction. Black spots are due to pitting from over-etching.

Figure 14 - a) SEM image of the plating, bulk material, and the interface between the plating and the bulk material. A line scan is overlaid on the SEM image. Elemental maps from EDS for b) $\mathrm{Ag}, \mathrm{c}$ ) $\mathrm{Cu}, \mathrm{d}$ ) $\mathrm{Ni}$, and e) $\mathrm{Zn}$ which show no segregation in the bulk material or plating and a very sharp interface between the plating and the bulk material with little diffusion. 

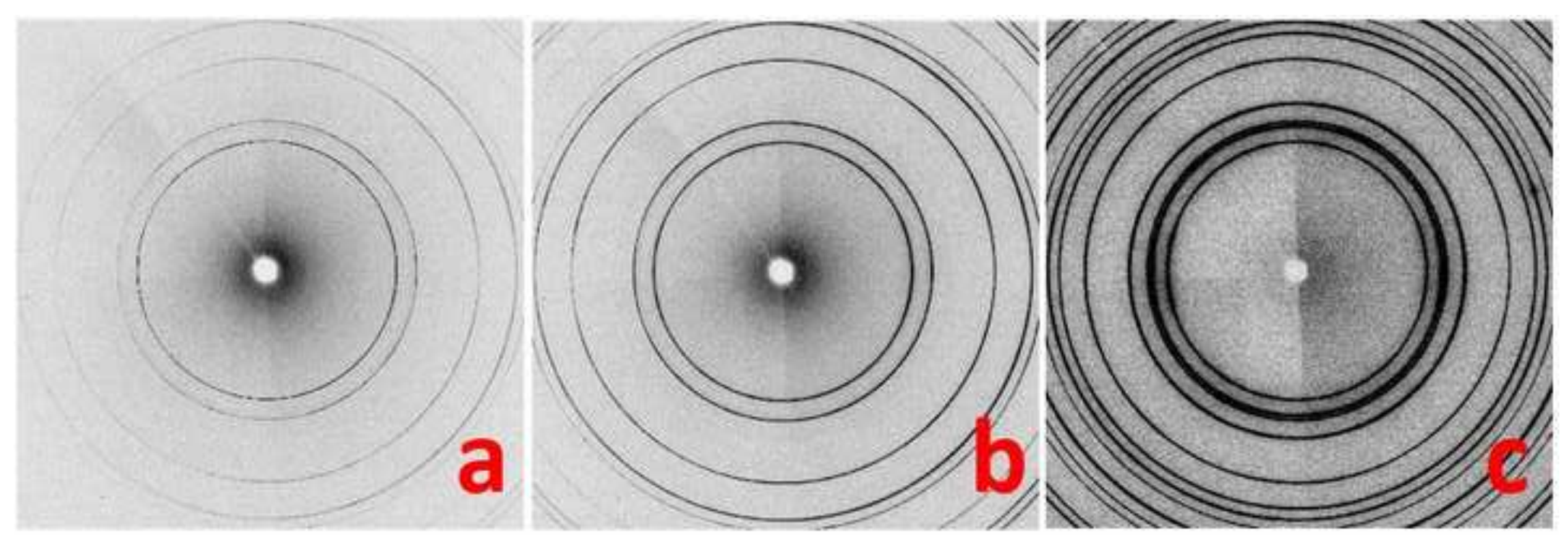
normalized intensity with $10 \mu \mathrm{m}$ offset per spectrum

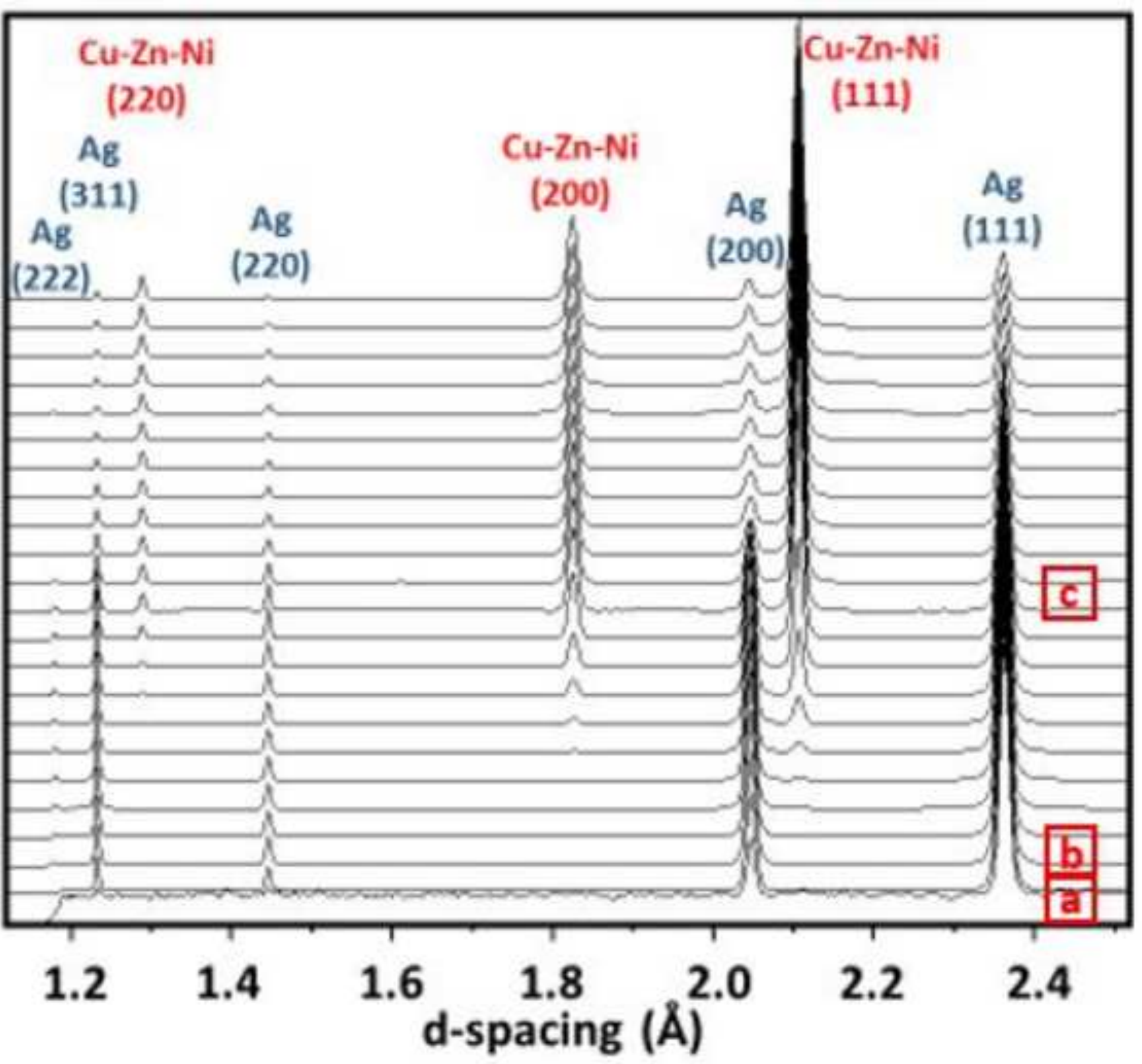

$160 \mu \mathrm{m}$ $140 \mu \mathrm{m}$ $120 \mu \mathrm{m}$ $100 \mu \mathrm{m}$ $80 \mu \mathrm{m}$ $60 \mu \mathrm{m}$ $40 \mu \mathrm{m}$ $20 \mu \mathrm{m}$ $0 \mu \mathrm{m}$ 


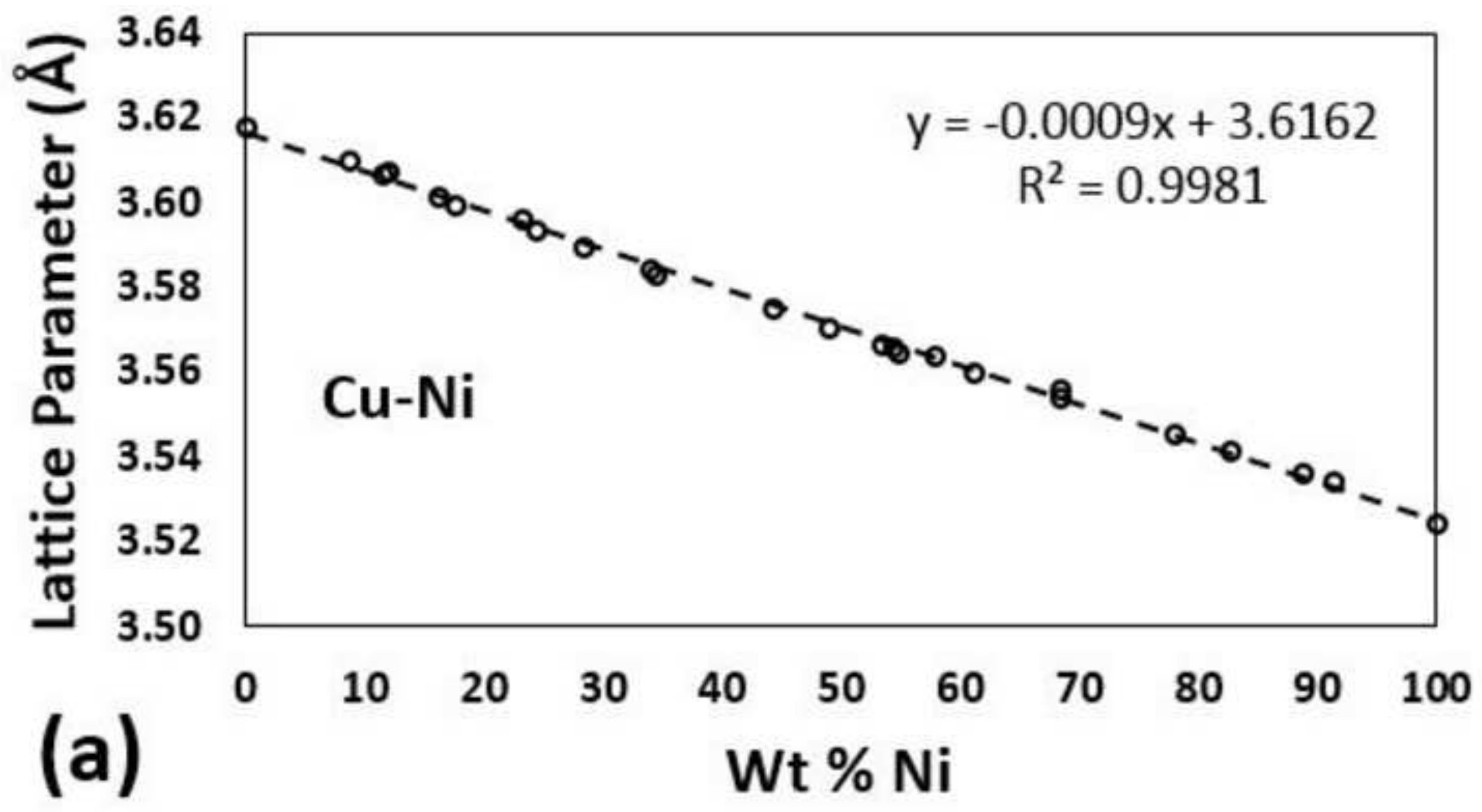




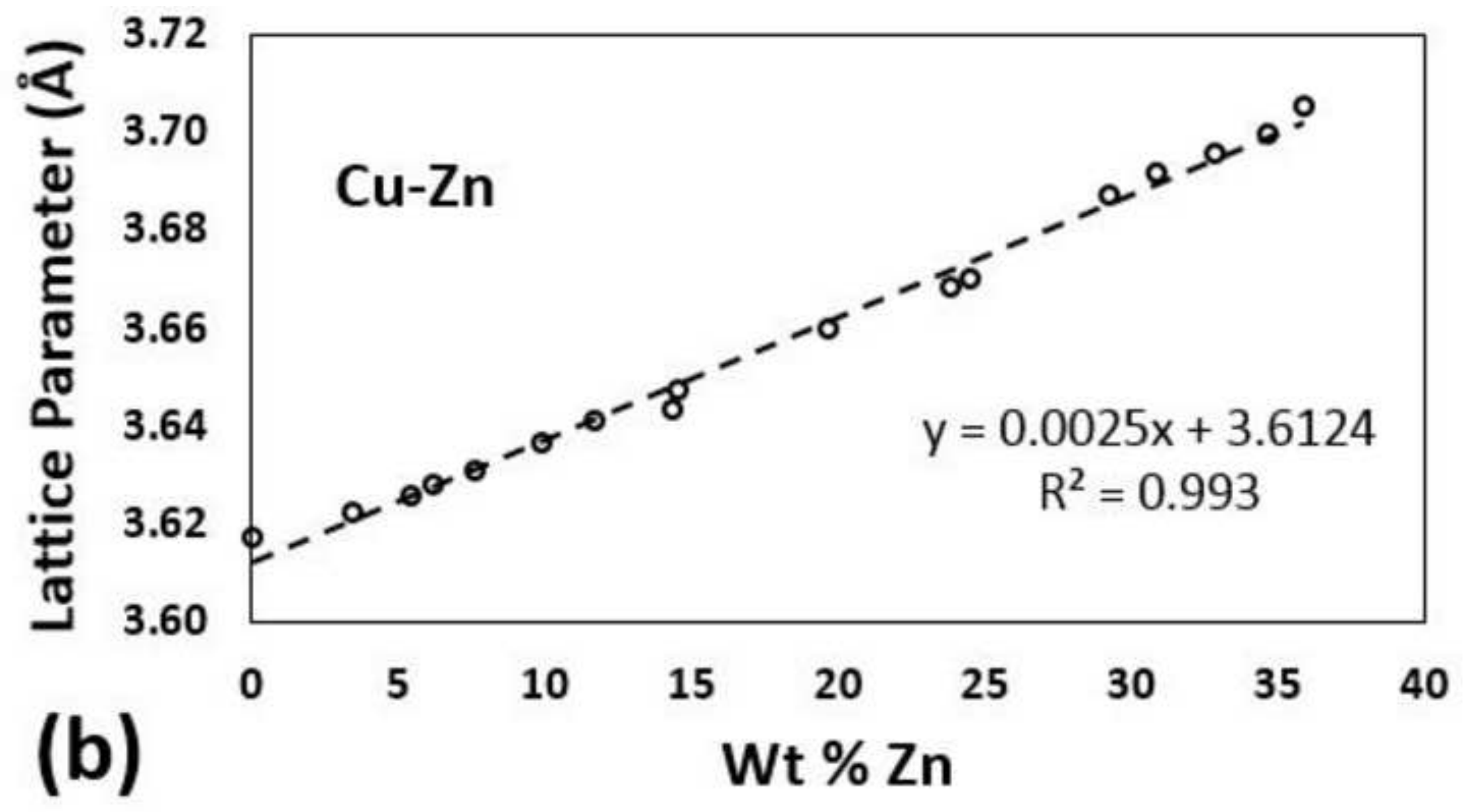




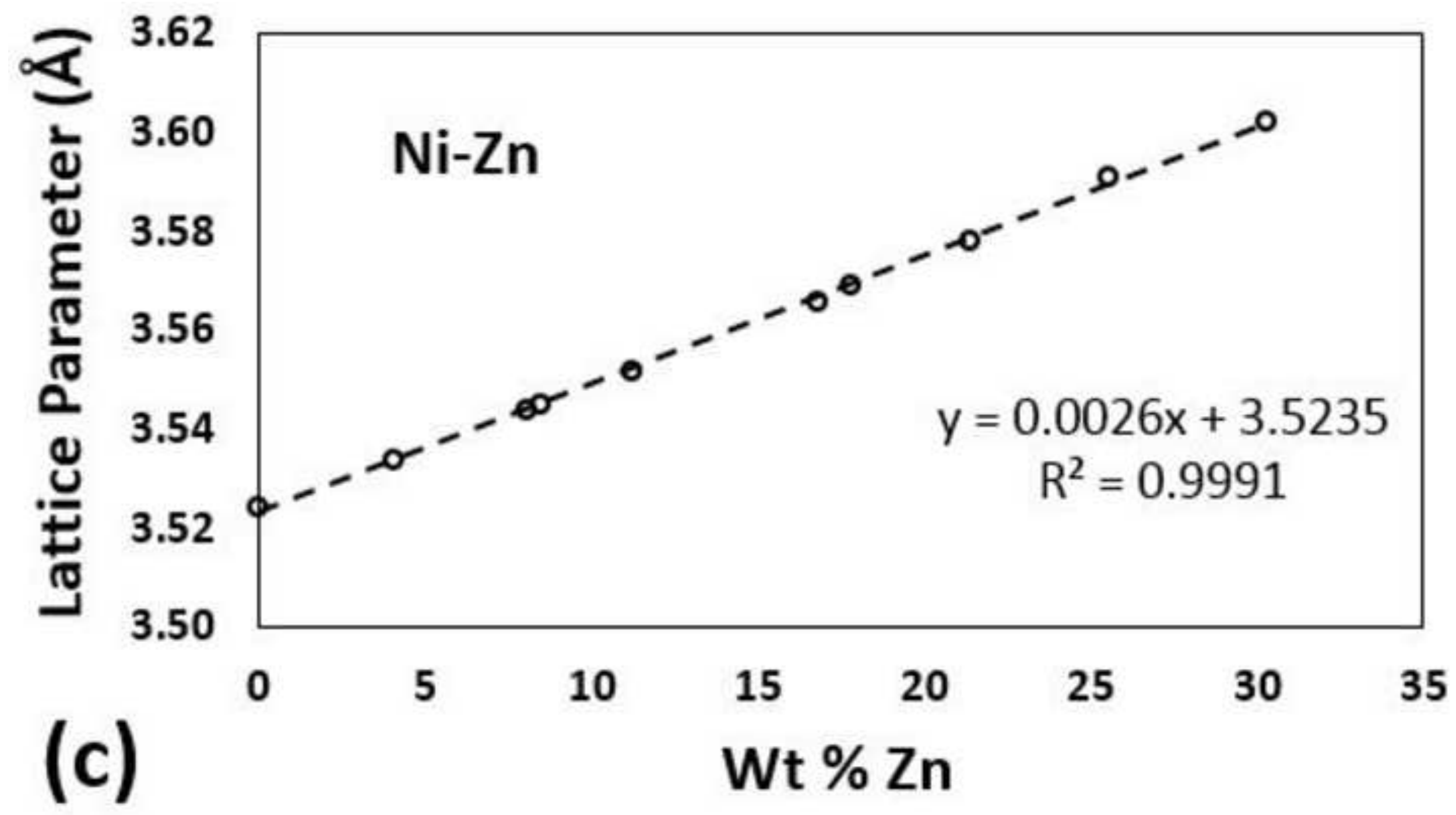




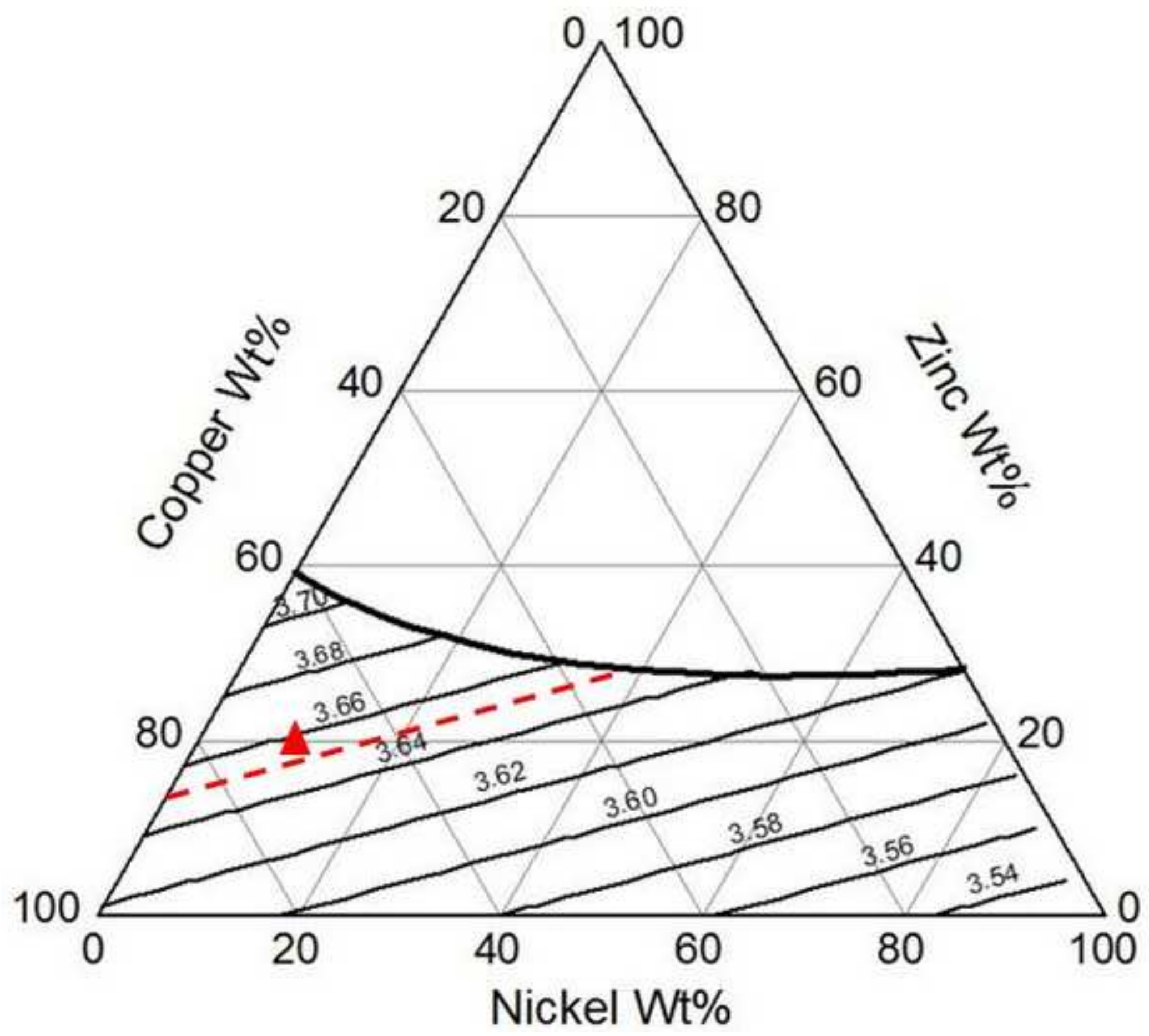




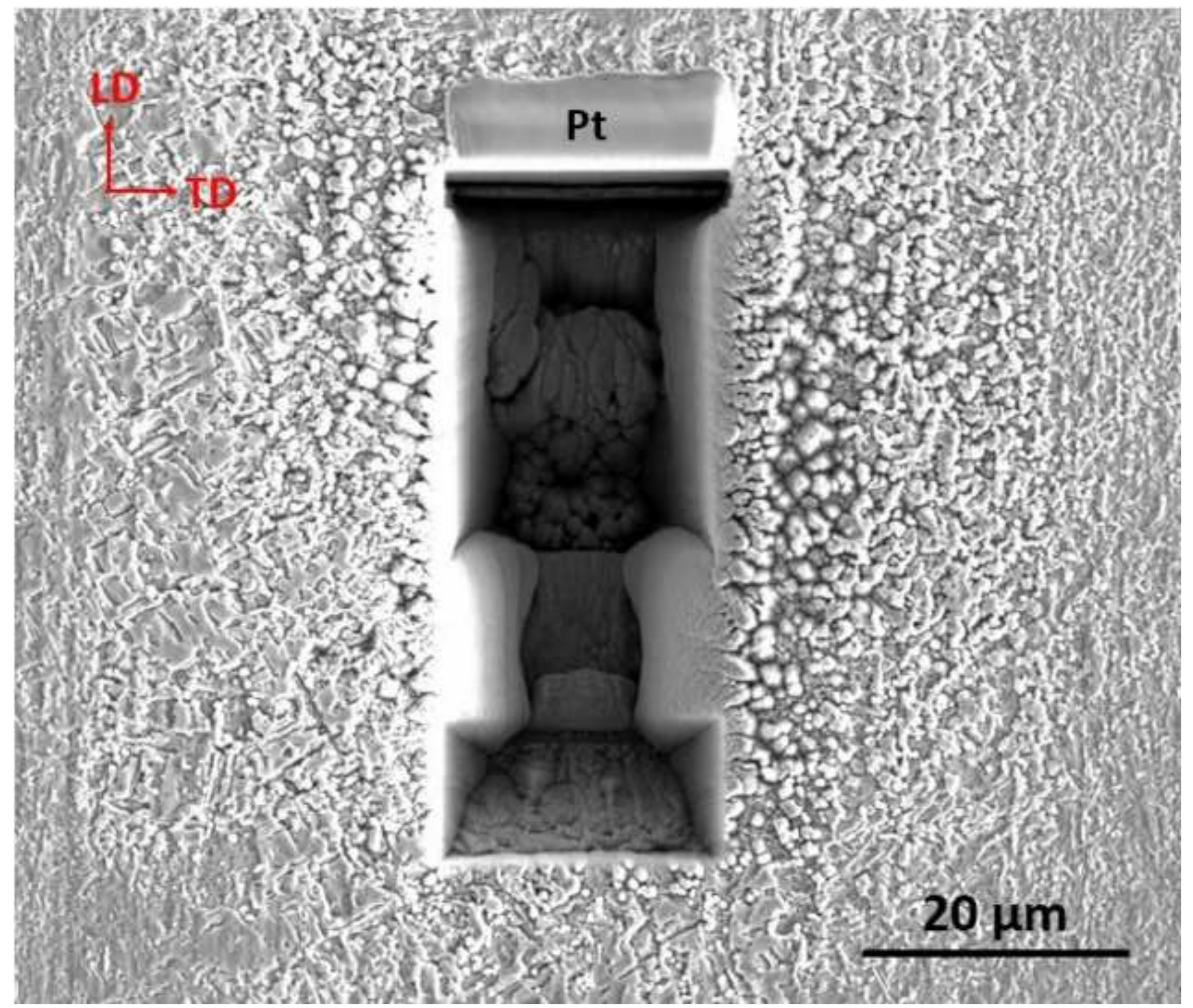




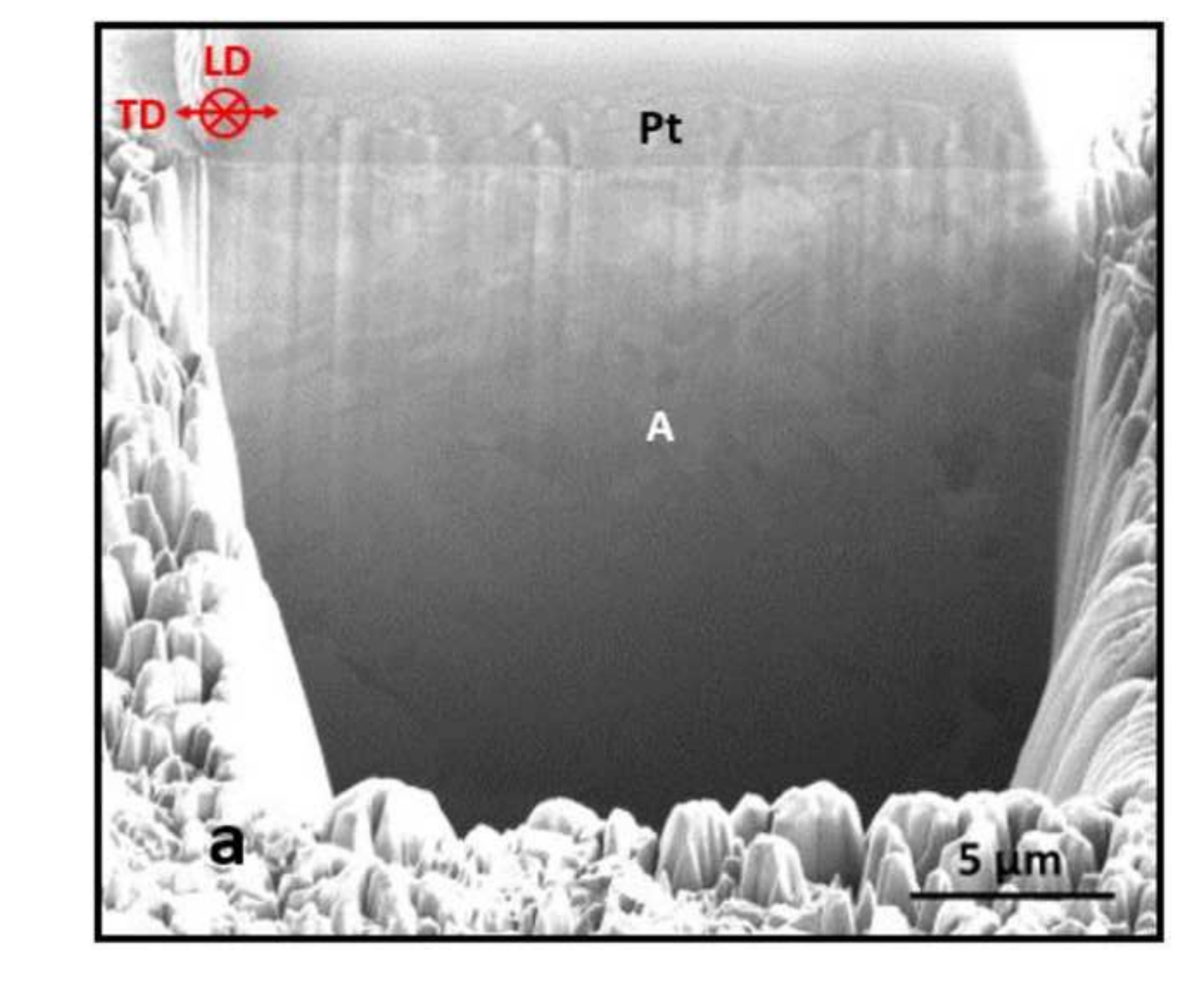

a

\section{.}

\section{西}
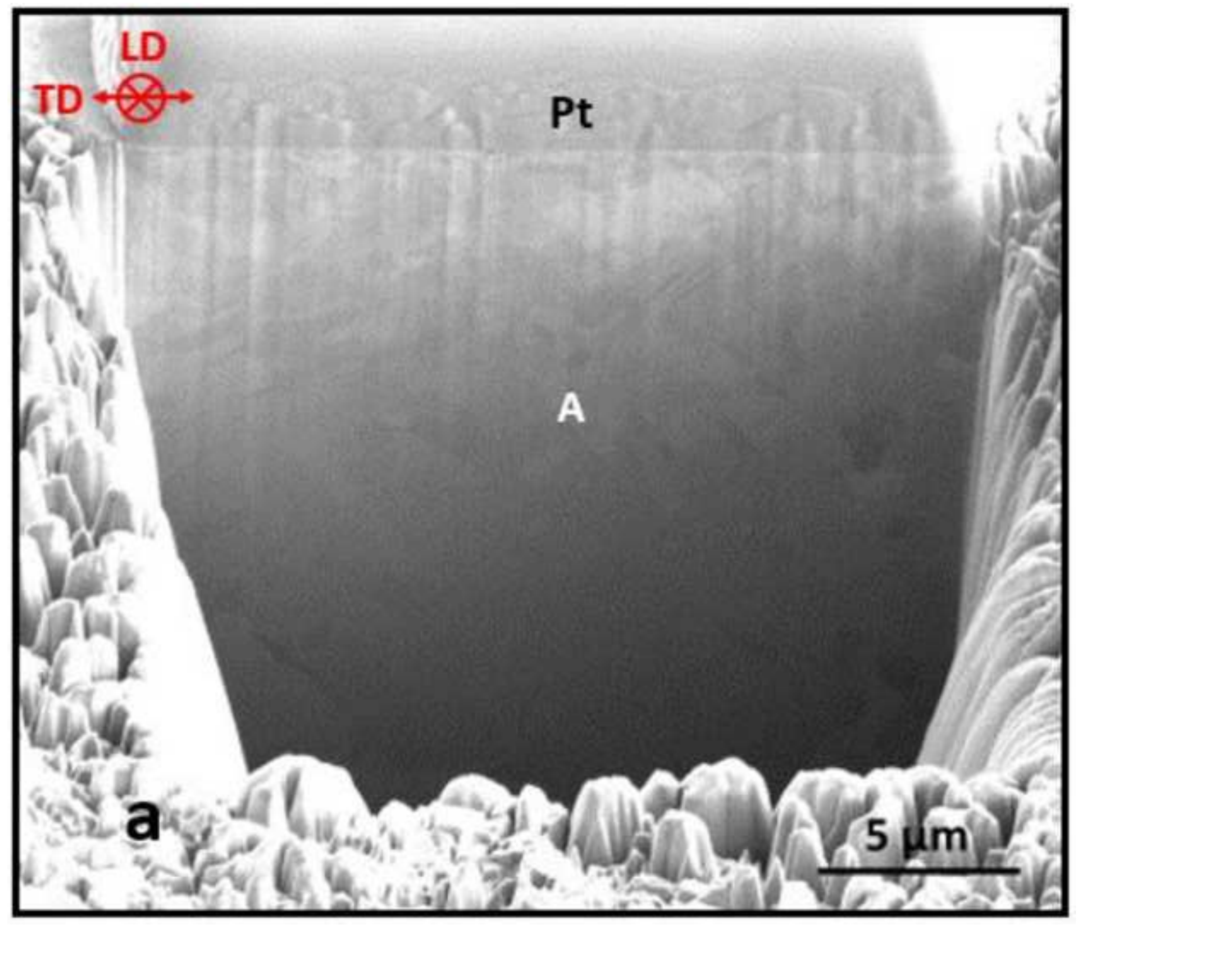

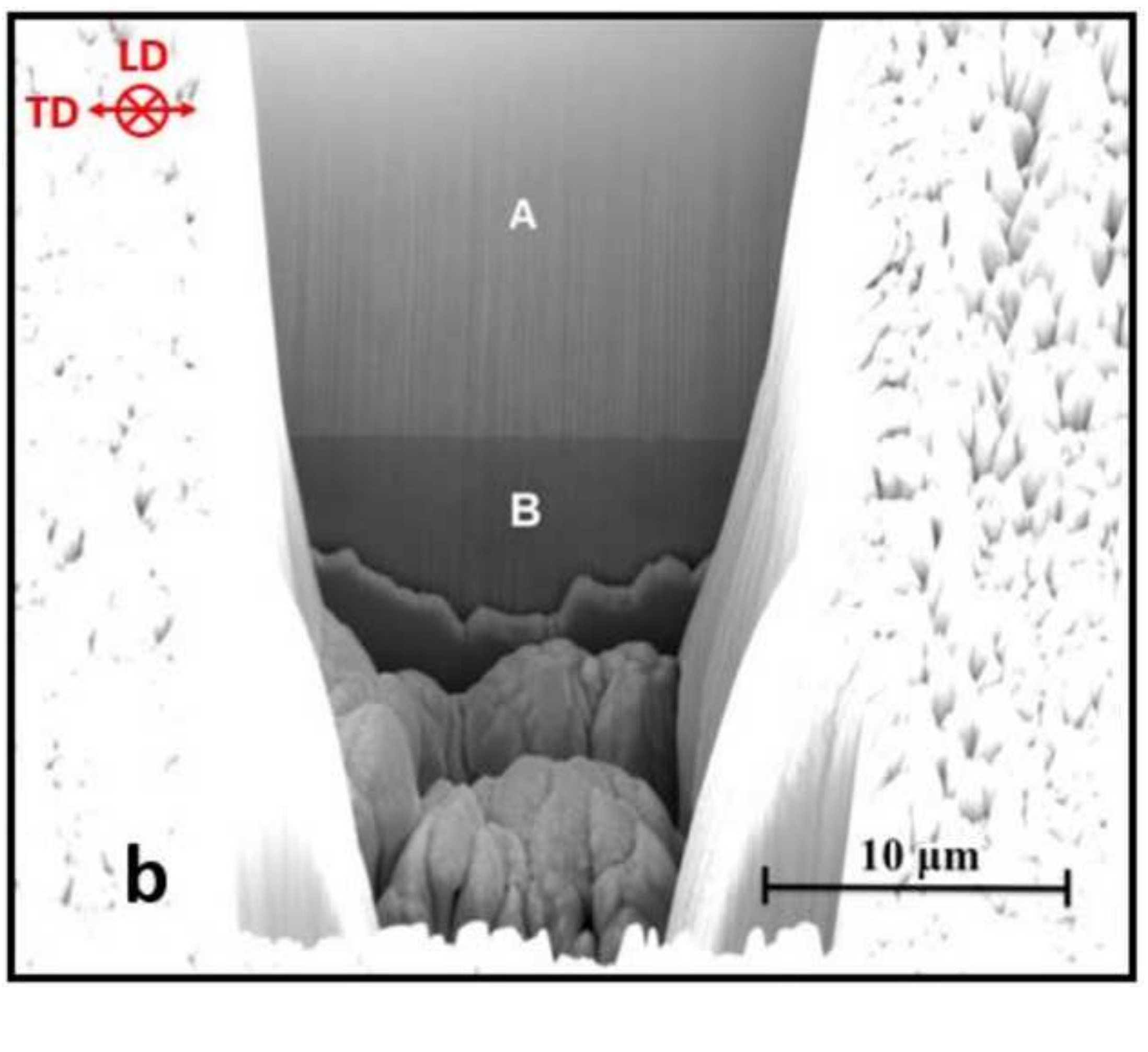


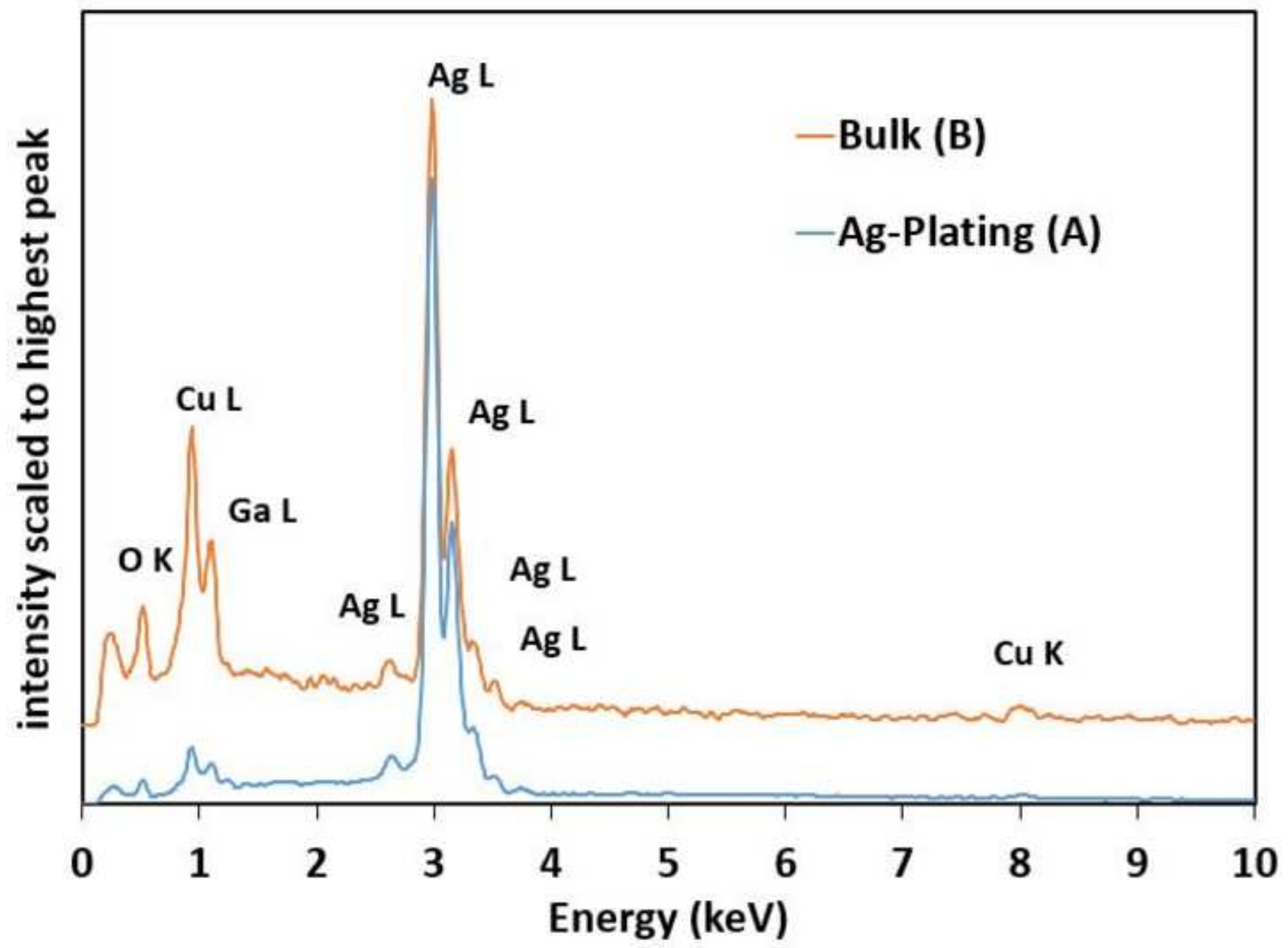




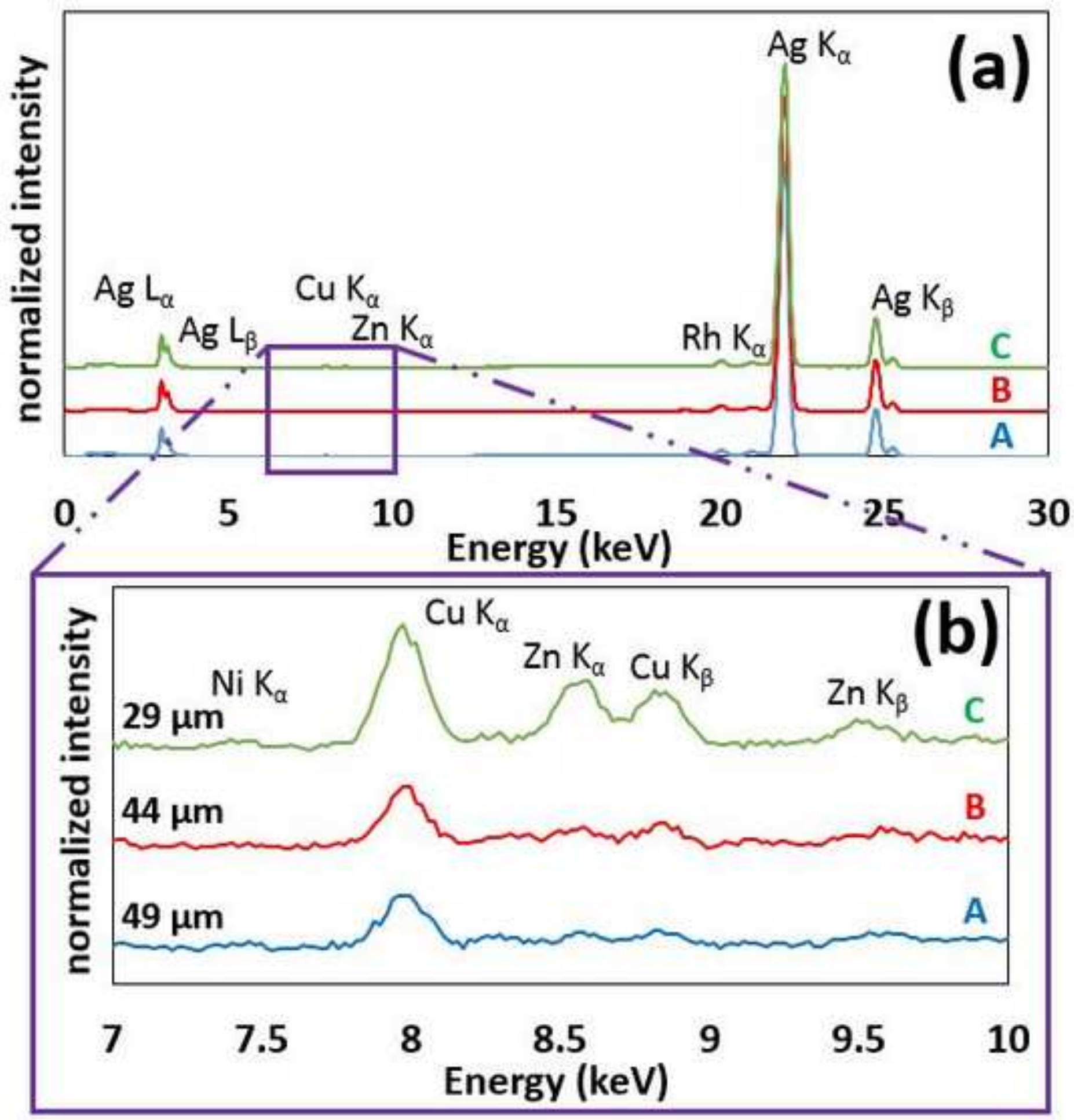



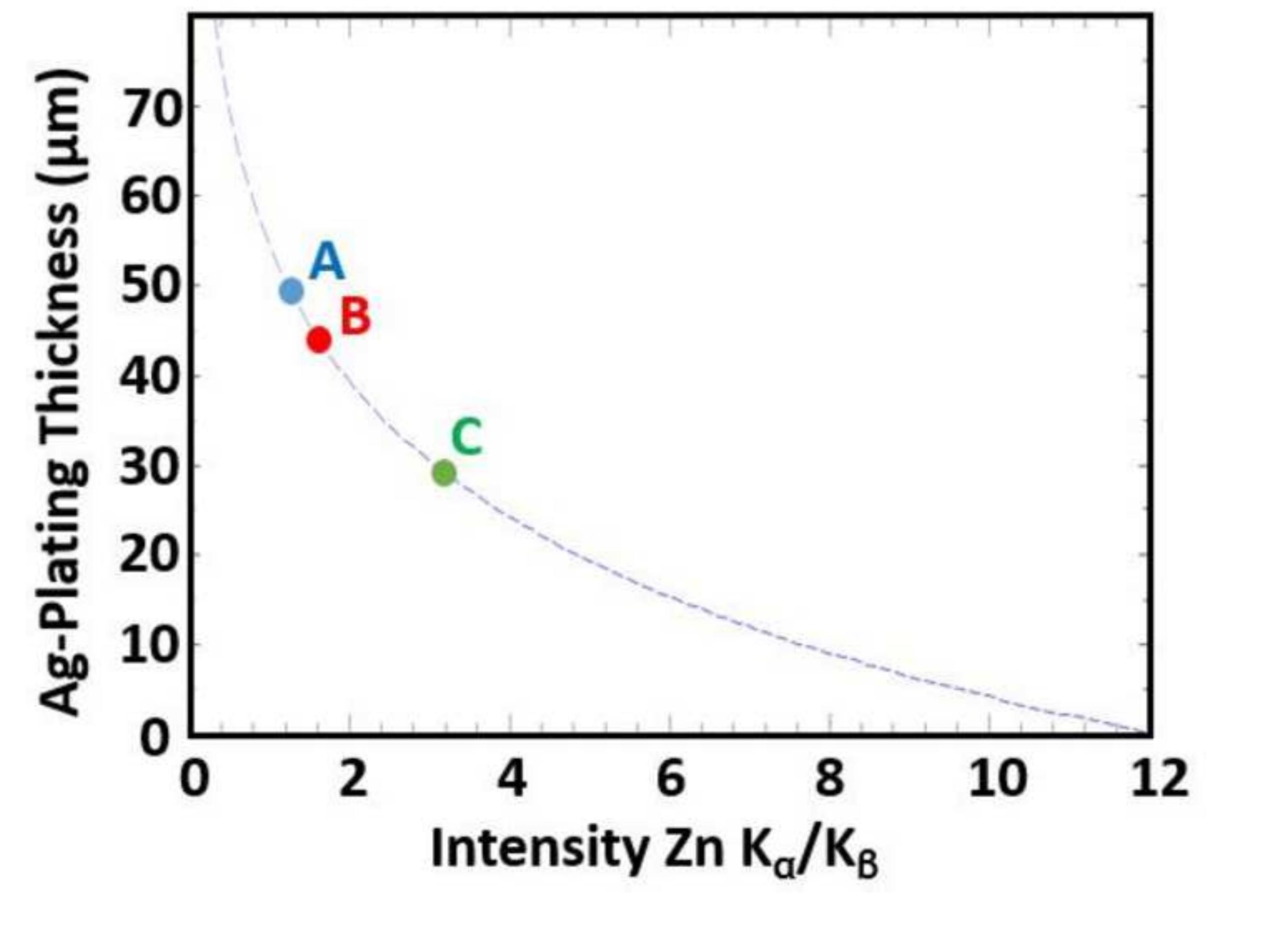
Figure $13 b$

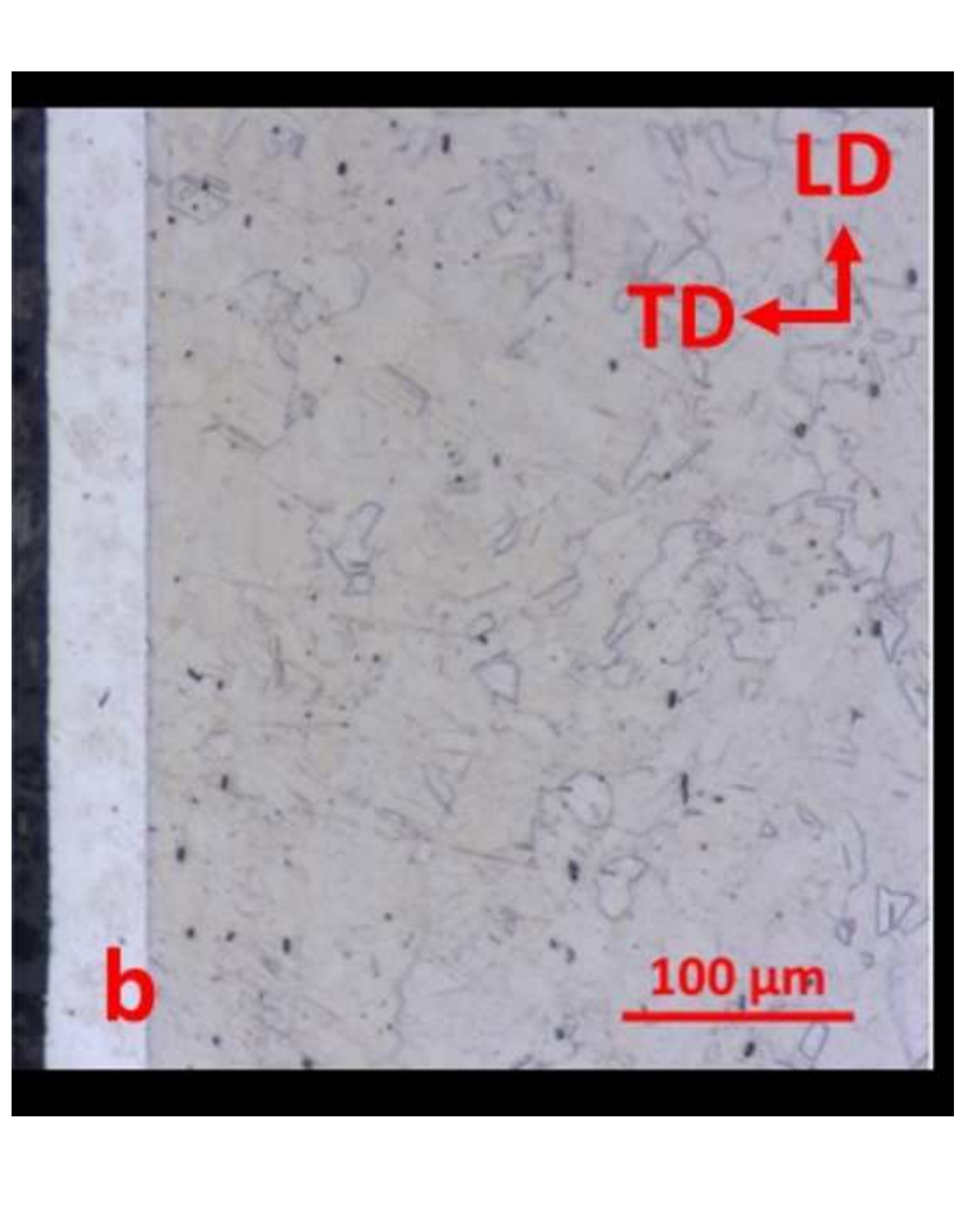

\section{Figure 13}

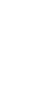

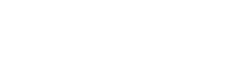



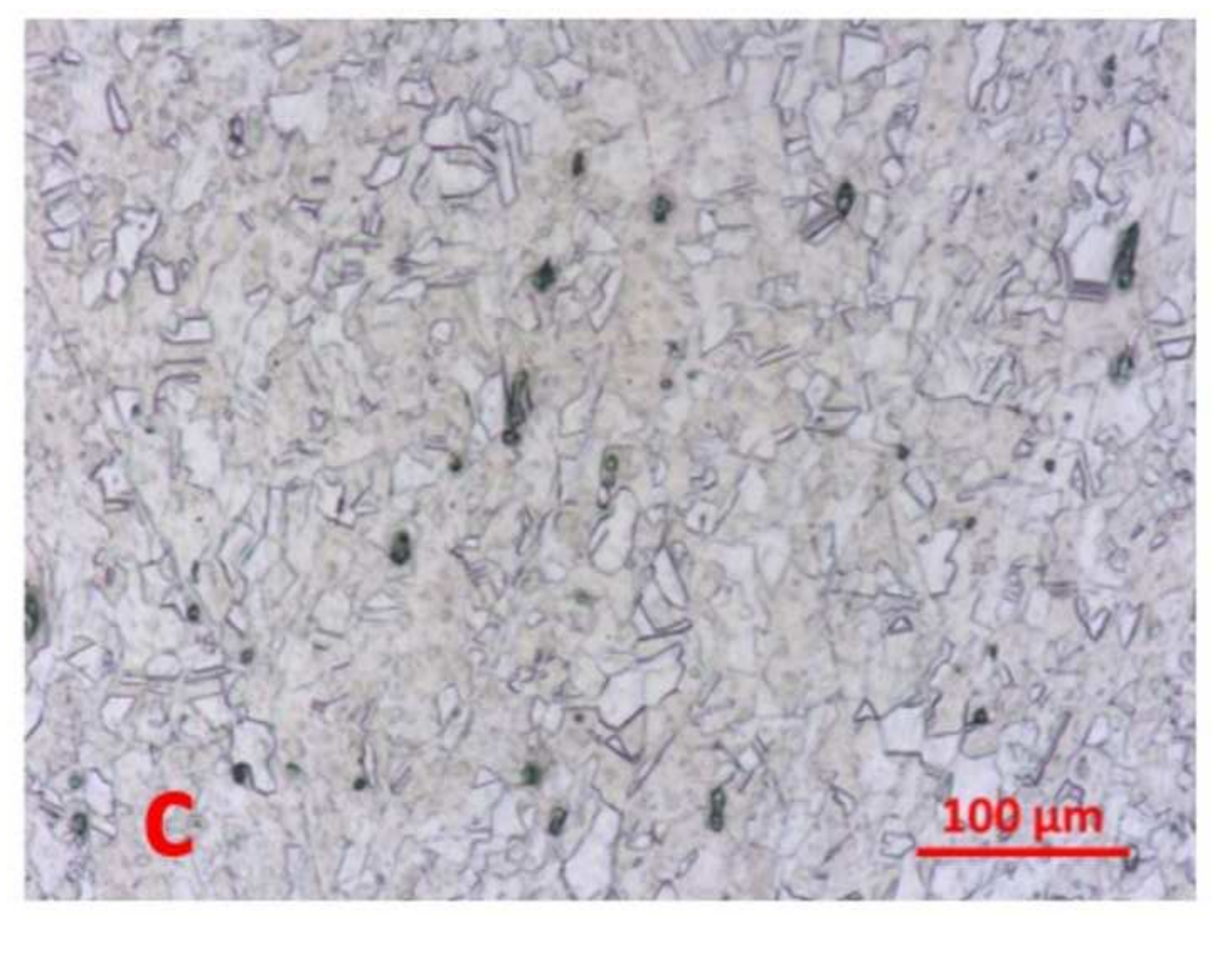

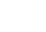




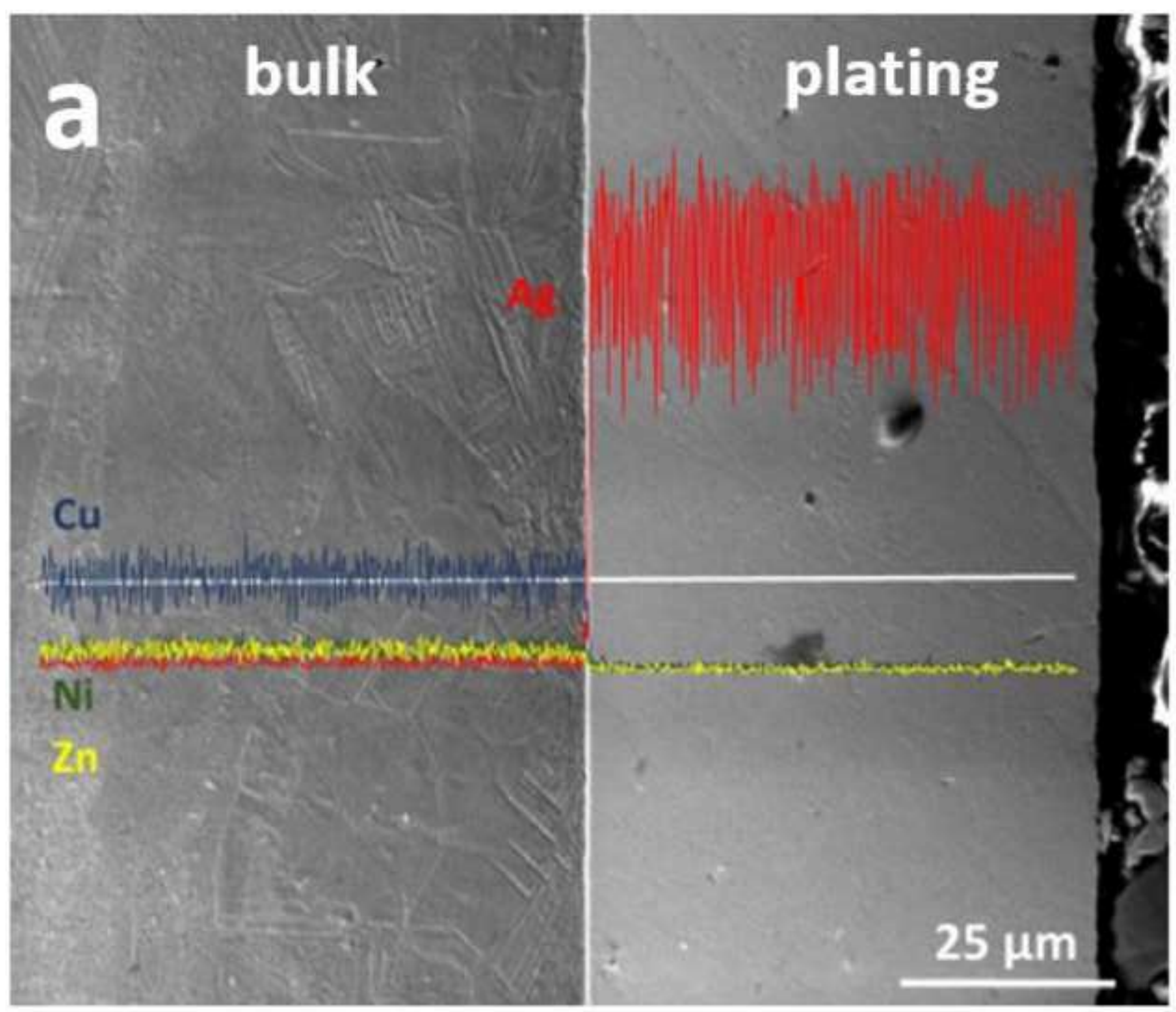

\section{$\mathrm{Cu}$}

11 1

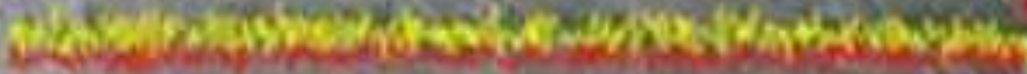
$\mathrm{Ni}$

$\mathrm{Zn}$

\section{bulk \\ plating :}

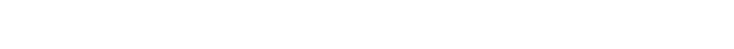

.

.




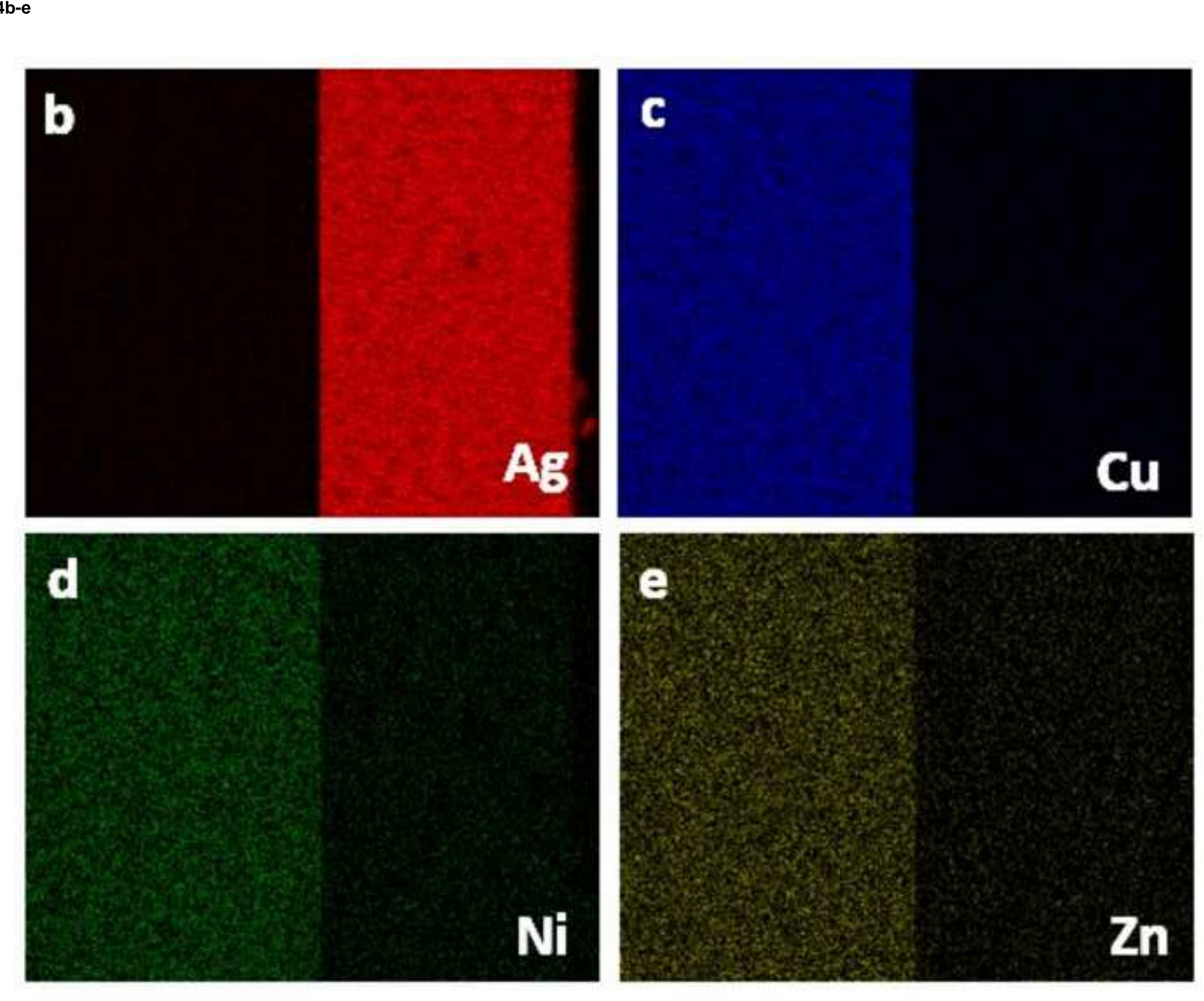
.

b

C 